\title{
Study on the Stability of the Coal Seam Floor above a Confined Aquifer Using the Structural System Reliability Method
}

\author{
Haifeng Lu, ${ }^{1,2}$ Xiuyu Liang $\mathbb{D}^{3,4}$ Nan Shan, ${ }^{5}$ and You-Kuan Zhang $\mathbb{D}^{3,4}$ \\ ${ }^{1}$ College of Earth and Environment, Anhui University of Science and Technology, Huainan, Anhui 232001, China \\ ${ }^{2}$ State Key Laboratory of Coal Resources and Safe Mining, China University of Mining and Technology (Beijing), \\ Beijing 100083, China \\ ${ }^{3}$ State Environmental Protection Key Laboratory of Integrated Surface Water-Groundwater Pollution Control, School of \\ Environmental Science and Engineering, Southern University of Science and Technology, Guangdong 518055, China \\ ${ }^{4}$ Guangdong Provincial Key Laboratory of Soil and Groundwater Pollution Control, Southern University of Science and Technology, \\ Shenzhen, Guangdong 518055, China \\ ${ }^{5}$ Nanjing Institute of Environmental Sciences, Ministry of Environmental Protection of the People's Republic of China, Nanjing, \\ Jiangsu 210042, China
}

Correspondence should be addressed to Xiuyu Liang; liangxy@sustc.edu.cn

Received 10 July 2018; Accepted 16 September 2018; Published 12 November 2018

Guest Editor: Mandadige S. A. Perera

Copyright (C) 2018 Haifeng Lu et al. This is an open access article distributed under the Creative Commons Attribution License, which permits unrestricted use, distribution, and reproduction in any medium, provided the original work is properly cited.

\begin{abstract}
A quantitative method of structural system reliability was proposed to study the influence of random rock mechanical parameters and loads on the stability of the coal seam floor above confined aquifers. To obtain the reliability probability of the floor, two modes of water-resistant floor failure were suggested as follows: (1) mining completely removed the water-resistant key strata of the floor. In this case, the failure modes were of three main types: mining failure, confined water intrusion, and combined mining failure and intrusion. (2) Failure modes included shear and tensile failures when the thickness of the key strata was greater than 0 . On the basis of the elastic thin plate theory, the performance function that calculates the reliability probability of all modes could be obtained. The failure modes were regarded as the series system. The Monte Carlo method was employed to calculate the reliability probability of each failure mode and series system. The results showed that the random rock mechanical parameters and loads of the key strata significantly influence the antiwater inrush capacity of the floor. In addition, the water inrush coefficient and reliability probability can be simultaneously used as the evaluation indexes of water inrush risk. Both these indexes could improve the assessment of the reliability of the floor.
\end{abstract}

\section{Introduction}

Water inrush from mining floors above limestone aquifers, which usually have a high water pressure, is a problematic aspect of the hydrogeological and engineering geological domain of Chinese coalfields, and it critically threatens the production of coal mines. Therefore, water damage to the mine floor should be studied and the occurrence of water inrush accidents in coal mines, which is a difficult problem to solve, should be effectively curbed [1-3]. Several studies have attempted to investigate the problem of floor water inrush and have proposed various approaches, such as the water inrush coefficient [4-6], plate model [7-9], down three zones [10-12], and key strata [13-17]. These studies revealed the mechanism of water inrush considering various aspects and provided positive guidance for mine safety production. However, all of these studies only considered deterministic methods that could not reflect the true degree of security. The geological conditions of water-resistant floors are complicated, leading to the rock mechanic parameters and loads being uncertain, given that the safety in evaluating waterresistant floors by using deterministic methods is uncertain. In contrast, the reliability theory is more suitable for studying the stability of water-resistant floor in mining.

Research on the results of using the structural reliability method to analyze the stability of a water-resistant floor of 
a coal seam above a confined aquifer is lacking. The reliability analysis model of the floor with the water inrush coefficient as a performance index was established by $\mathrm{Du}$ et al. [18]. $\mathrm{Lu}$ et al. [19] and $\mathrm{Lu}$ and Yao [20] extended the model of $\mathrm{Du}$ et al. [18] by employing a remaining complete rock layer as a clamped beam. In their models, the limit water pressure of the beam's strength failure based on the theory of material mechanics and elastic mechanics was used as a performance function to calculate the reliability of the water-resistant floor stability. However, as mentioned above, such studies only focused on the water inrush caused by a single failure mode and did not consider the possibility that multiple failure modes could also cause water inrush. For example, tensile or shear failure may occur in effective water-resistant floors or mining failure type and progressive intrusion of confined water may occur in an ineffective water-resistant layer. On the other hand, the water inrush coefficient can only reflect two factors, namely, the water pressure and thickness of the water-resistant layer, when selecting a structure performance function. Nevertheless, the clamped beam model derived from the mechanics of materials has poor accuracy in the analysis of deep beams with a relatively short length and height. Although the accuracy of the elastic mechanics clamped beam model is high, the stress distribution at the end of the clamped beam cannot be precisely obtained, which results in considerable errors in the solution of the limit water pressure. The accuracy of the structural reliability analysis results mainly depends on the selection of the performance function. Thus, the results of the previous calculation are not completely reliable.

To reasonably reflect the reliability of the water-resistant floor's stability, this study first applies the key strata theory to consider the effect of geostress. The key strata of the floor are regarded as a rectangular plate with four sides clamped, and the elastic mechanics plate theory is used to derive the mechanics criterion of key strata destruction, which is considered a function of structural reliability analysis. On this basis, the failure modes of the water-resistant floor are analyzed, and the reliability probability of each failure mode is calculated through a simulation employing the Monte Carlo method. The failure modes are regarded as the series system, and the reliability probability of the water-resistant floor's stability system is obtained. The mean and variance of random variables, such as rock strength parameters and ground stress, are discussed through a case, and the influence of the position of the key strata on the reliability probability is analyzed. Finally, various failure modes and the system reliability of the water-resistant floor of a certain coal mine are analyzed and evaluated.

\section{Methodology}

2.1. Mechanics of Failure Forms of Key Strata. The vertical distance of the coal seam to the roof of the confined aquifer is called the water-resistant floor and has a thickness of $h$ (Figure 1(a)). Before coal seam mining, owing to the existence of natural cracks in the floor, the water rises along these natural cracks to a certain height under the action of hydrostatic pressure, a rise that is called the original progressive intrusion height of confined water. The height is generally small, as shown in Figure 1(a).

After the working face is mined, the mined-out area is formed and the weight of the overlying strata shifts to the coal and rock mass around the mined-out area to form a supporting pressure belt around the mined-out area. When the supporting pressure reaches or exceeds the ultimate strength limit of the rock floor, the rock mass in a certain range of the working face's floor is destroyed and the failure zone of the floor mining is formed (Figure 1(b)). At the same time, under the combined influence of mining and confined water, the cracks of the original intrusion zone extend further upward to form a progressive intrusion zone of confined water. The sum of the original and progressive intrusion belts is called the intrusion zone of confined water, and it has a maximum height of $h_{c}$. At present, the maximum value of this parameter is relatively larger in the structural fracture zone and is usually measured through actual measurements.

For the working face, as shown in Figure 1, the maximum failure depth $h_{\mathrm{a}}$ of floor mining during the initial stage can be determined according to the fracture mechanics theory. The stope is assumed to be a crack in the internal part of the infinite rock. For the stope, the mining thickness is much smaller than the mining width. Consequently, the calculation of stress can be simplified as a plane problem, and the maximum failure depth $h_{\mathrm{a}}$ in the floor of the stope can be calculated by (1) as follows [21]:

$$
h_{\mathrm{a}}=\frac{1.57 \gamma^{\prime 2} H^{2} a(1-\sin \phi)^{2}}{16 c^{2} \cos ^{2} \phi},
$$

where $\gamma^{\prime}$ is the average weight of the overlying coal seam layer $\left(\mathrm{kN} / \mathrm{m}^{3}\right), H$ is the cover depth of the coal seam $(\mathrm{m}), c$ and $\varphi$ are the average cohesion (MPa) and internal friction angle $\left({ }^{\circ}\right)$ of the floor rock, respectively, and $a$ is the width of the working face $(\mathrm{m})$.

After solving the depth $h_{\mathrm{a}}$ of the mining failure of the floor, the thickness $h_{\mathrm{b}}$ of the remaining intact rock stratum can be obtained according to the instruction height $h_{c}$ of the confined water (Figure 2). The water inrush from the floor plate depends mainly on the antiwater pressure capacity of the remaining intact rock stratum. The key strata theory states that a certain rock mass with reasonable strength and water resistance in the remaining complete rock belt, which is called the key strata of the water-resistant floor, has a thickness $h_{\mathrm{k}}$. The distance between the floor of the key strata and the floor of the coal seam is $h^{\prime}$ (Figure 1(b)). Whether the confined water can break into the working face depends mainly on the water-resistant performance of the key strata, which are deformed similar to a plate under water pressure. As shown in Figure 2, under normal mining conditions, for the longwall mining face, the key strata of the floor consist of a rectangular plate with four edges clamped when the coal seam is near horizontal or gently inclined, and a flat plate model is established.

The setting of the $x-y$ coordinate surface coincides with the middle plane of the plate, the origin of the coordinate lies in the center of the plate, the $o z$ axis is vertically downward 


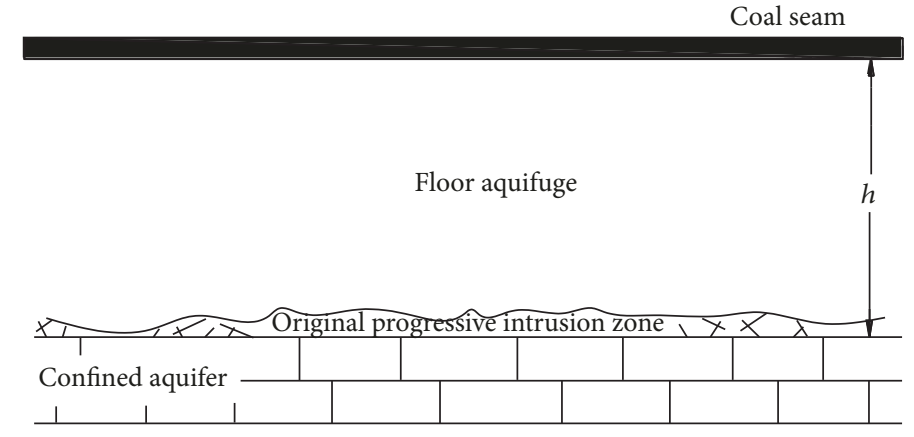

(a)

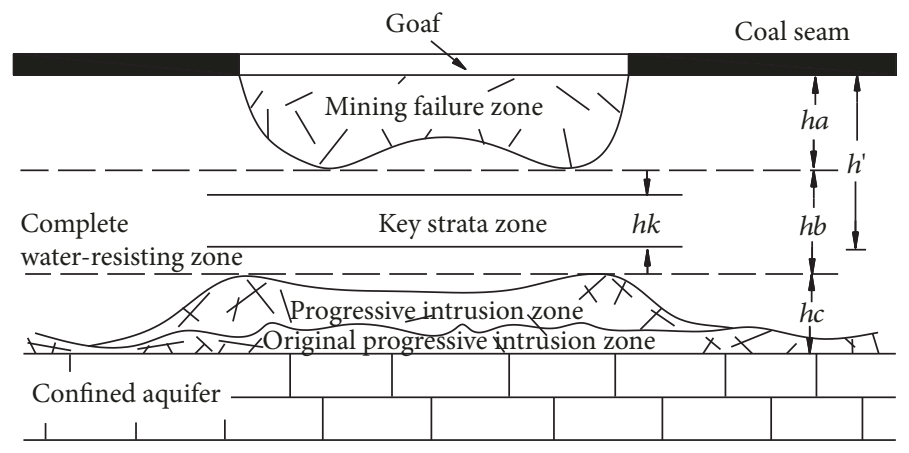

(b)

FIGURE 1: Schematic map of floor damage during first pressure in mining above the confined aquifer. (a) Original intrusion zone of confined water before mining. (b) Intrusion zone of confined water, failure zone of the floor, and key strata.

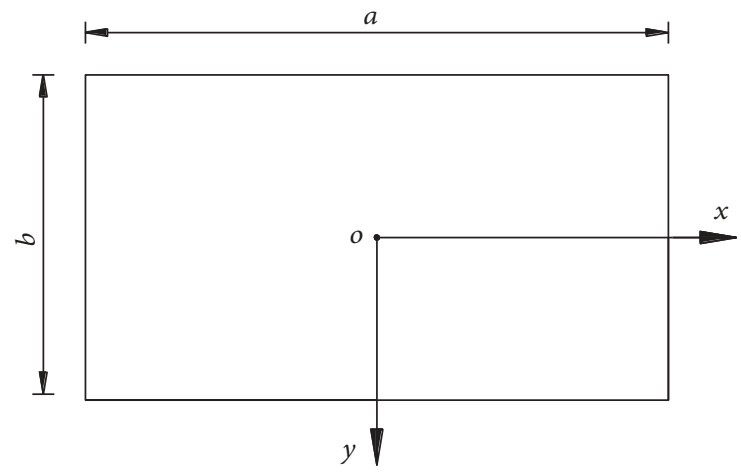

(a)

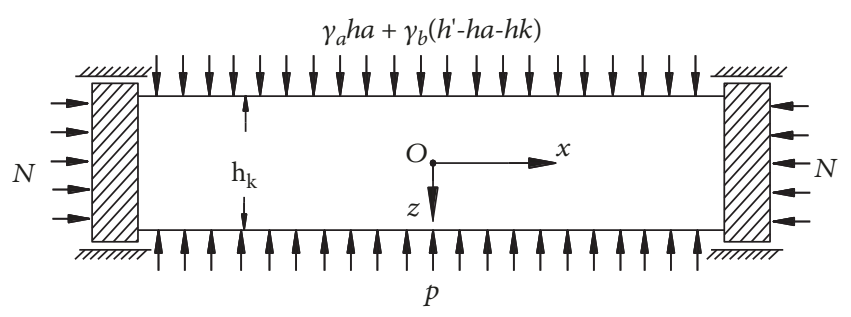

(b)

Figure 2: (a) Plan of plate model and (b) profile map of plate model.

toward the middle plane, and the thickness of the plate is the same as that of the water-resistant key strata $h_{\mathrm{k}}$. The $x$-direction is the width of the working face with length $a$. The $y$ direction is the advancing direction of the working face with length $b$.

The average weight of the mining failure belt of the floor is $\gamma_{\mathrm{a}}$; the average weight of the remaining intact rock layer is $\gamma_{\mathrm{b}}$; the average weight of the key strata is $\gamma_{\mathrm{k}}$; and $\mu_{\mathrm{k}}, E_{\mathrm{k}}, \varphi_{\mathrm{k}}$, and $c_{\mathrm{k}}$ denote Poisson's ratio, the elastic modulus, the internal friction angle, and the cohesive strength, respectively. The plate of the upper part is subjected to the self-weight $\gamma_{\mathrm{a}}$ $h_{\mathrm{a}}$ of the floor's mining fracture belt and the self-weight $\gamma_{\mathrm{b}}$ $\left(h^{\prime}-h_{\mathrm{a}}-h_{\mathrm{k}}\right)$ of the rock layer, which is obtained from the difference between the remaining intact rock belt of the floor and the key strata. The lower part is subjected to uniform water pressure $p$. The self-weight of the key strata is regarded as the surface force $\gamma_{\mathrm{k}} h_{\mathrm{k}}$ on the plate. Therefore, the lower part of the key strata is subjected to surface forces $q=p+\gamma_{\mathrm{b}}$ $h_{\mathrm{a}}-\gamma_{\mathrm{b}} h^{\prime}-\gamma_{\mathrm{k}} h_{\mathrm{k}}+\gamma_{\mathrm{b}} h_{\mathrm{k}}$. It is interesting to note that the upper rock mass of the water-resisting zone is destroyed at this point; we believe that it will not bear any additional stress and will be in harmony with the key strata as it bends upward. Therefore, it is feasible and controllable to consider the dead weight of the upper rock mass of the key 
strata as the external load in this model. The horizontal stress $N$ acts around the plate. A uniform load is assumed in the calculation. The expression is shown as (2).

$$
N=k_{0} \gamma^{\prime} H
$$

where $k_{0}$ is the lateral pressure coefficient, $H$ is the cover depth of the coal seam $(\mathrm{m})$ considered in the paper, and $\gamma^{\prime}$ is the average weight of the overlying coal seam layer $\left(\mathrm{kN} / \mathrm{m}^{3}\right)$.

Considering that the thick plate theory is not mature in mechanics, the mechanical analysis of the key strata is conducted by using the elastic thin plate theory. Given that the key strata are not damaged by mining, they can still be regarded as a continuous medium and assumed to be homogeneously isotropic. In China, the width of the longwall working face is $150-240 \mathrm{~m}$, the first-time roof weighting step of the working face is approximately $30-40 \mathrm{~m}$, and the water inrush of the floor often occurs during the first-time roof weighting step [8]. Meanwhile, the layer thickness of the coal-bearing sedimentary rock mass is generally below $10 \mathrm{~m}$, and the plate model of the water-resistant key strata during initial mining can satisfy the general conditions of the thin plate (the ratio of thickness to width is not greater than 1/5).

Under the combined effect of the longitudinal load $N$ and transverse load $q$ at the lower part of the key strata, the differential equation of thin plate bending can be expressed as $[22,23]$

$$
D\left(\frac{\partial^{4} w}{\partial x^{4}}+2 \frac{\partial^{4} w}{\partial x^{2} \partial y^{2}}+\frac{\partial^{4} w}{\partial y^{4}}\right)=q+N h_{k}\left(\frac{\partial^{2} w}{\partial x^{2}}+\frac{\partial^{2} w}{\partial y^{2}}\right) .
$$

In the equation, $w$ is the deflection of the thin plate, and $D=E_{k} h_{k}^{3} / 12\left(1-\mu_{k}^{2}\right)$ is the bending stiffness of the thin plate.

The boundary conditions of the rectangular thin plate with four sides clamped are

$$
\begin{array}{ll}
(w)_{x=-a / 2, a / 2}=0 & \left(\frac{\partial w}{\partial x}\right)_{x=-a / 2, a / 2}=0, \\
(w)_{y=-b / 2, b / 2}=0 & \left(\frac{\partial w}{\partial y}\right)_{y=-b / 2, b / 2}=0 .
\end{array}
$$

The above differential equations are difficult to solve accurately and can be solved by the Ritz method. The deflection function of the middle plane of the bending plate is

$$
\begin{aligned}
w(x, y)= & \sum_{m} \sum_{n} \frac{w_{m n}}{4}\left[1-(-1)^{m} \cos \frac{2 m \pi x}{a}\right] \\
& \cdot\left[1-(-1)^{n} \cos \frac{2 n \pi y}{b}\right], \quad m=n=1,3,5 \ldots
\end{aligned}
$$

where $w_{m n}$ is the undetermined coefficient of the deflection function.

Obviously, the deflection function $w$ can satisfy the boundary conditions of the clamped plate. Because the above equation converges quickly, the equation can be replaced by the first term and can satisfy the precision requirements of mining engineering; that is,

$$
\begin{aligned}
w(x, y) & =\frac{w_{11}}{4}\left[1+\cos \frac{2 \pi x}{a}\right]\left[1+\cos \frac{2 \pi y}{b}\right] \\
& =w_{11} \cos ^{2} \frac{\pi x}{a} \cos ^{2} \frac{\pi y}{b} .
\end{aligned}
$$

According to the Ritz method, the coefficient of deflection function $w_{11}$ of the key strata under the combined vertical and horizontal loads can be obtained as follows:

$$
w_{11}=\frac{q a^{2} b^{2} \pi^{2}}{D \pi^{2}\left(\left(3 a^{2} / b^{2}\right)+\left(3 b^{2} / a^{2}\right)+2\right)-3 / 4 N h_{k}\left(a^{2}+b^{2}\right)} .
$$

Thus, the deflection function, $w(x, y)$, of the key strata of the mining floor is as follows:

$w(x, y)=\frac{q a^{2} b^{2} \pi^{2}\left(\cos ^{2}(\pi x / a) \cos ^{2}(\pi y / a)\right)}{D \pi^{2}\left(\left(3 a^{2} / b^{2}\right)+\left(3 b^{2} / a^{2}\right)+2\right)-3 / 4 N h_{k}\left(a^{2}+b^{2}\right)}$.

Equation (8) shows that the deflection of the key strata increases under the action of horizontal ground stress. In light of the elastic thin plate theory, the stress expression in the key strata of water resistance under the vertical and horizontal loads can be obtained as follows (the compressive stress is positive and the tensile stress is negative):

$$
\left\{\begin{array}{l}
\sigma_{x}=A\left[b^{2} \cos ^{2} \frac{\pi y}{b}\left(2 \cos ^{2} \frac{\pi x}{b}-1\right)+\mu a^{2} \cos ^{2} \frac{\pi x}{b}\left(2 \cos ^{2} \frac{\pi y}{b}-1\right)\right]+N \\
\sigma_{y}=A\left[a^{2} \cos ^{2} \frac{\pi x}{a}\left(2 \cos ^{2} \frac{\pi y}{b}-1\right)+\mu b^{2} \cos ^{2} \frac{\pi y}{b}\left(2 \cos ^{2} \frac{\pi x}{a}-1\right)\right]+N \\
\tau_{x y}=-2 A a b(1-\mu) \cos \frac{\pi x}{a} \cos \frac{\pi y}{b} \sin \frac{\pi x}{a} \sin \frac{\pi y}{b}
\end{array}\right.
$$


In the following formula,

$$
A=\frac{24 D q h_{k}^{3} z}{\pi^{2} D\left(\left(3 a^{2} / b^{2}\right)+\left(3 b^{2} / a^{2}\right)+2\right)-(3 / 4) N h_{k}\left(a^{2}+b^{2}\right)} .
$$

Equation (9) shows that the stress component of the key strata is linearly distributed along the plate thickness under longitudinal and lateral loads, and the maximum value is located on the upper and lower surfaces of the plate $\left(z=-h_{\mathrm{k}} / 2, h_{\mathrm{k}} / 2\right)$. The stress distribution law of the key strata is discussed below.

With the values of $a=120 \mathrm{~m}, b=30 \mathrm{~m}, h_{\mathrm{k}}=6 \mathrm{~m}, q=3$ MPa, $\gamma_{\mathrm{k}}=25 \mathrm{kN} / \mathrm{m}^{3}, E_{\mathrm{k}}=5 \mathrm{GPa}, \mu_{\mathrm{k}}=0.3, z=-h_{\mathrm{k}} / 2$, and $N$ $=5 \mathrm{MPa}$, the distributions of $\sigma_{\mathrm{x}}, \sigma_{\mathrm{y}}$, and $\tau_{\mathrm{xy}}$ under vertical and horizontal loads in the key strata can be obtained by using (9) and (10), as shown in Figure 3 (herein, only the condition of the upper surface $z=-h_{\mathrm{k}} / 2$ in the key strata is analyzed, and the stress of the lower surface follows an opposite distribution law).

From the analysis of Figure 3 and (8), the center point $\left(x=0, y=0, z=-h_{\mathrm{k}} / 2\right)$ in the upper surface of the key strata experiences tensile stress with maximum values of $\sigma_{\mathrm{x}}=5.08 \mathrm{MPa}$ and $\sigma_{\mathrm{y}}=23.34 \mathrm{MPa}$. The midpoint $(0, \pm 15$, $\left.\mathrm{z}=-h_{\mathrm{k}} / 2\right)$ of the long edge in the key strata experiences compressive stress with maximum values of $\sigma_{\mathrm{x}}=13.34 \mathrm{MPa}$ and $\sigma_{\mathrm{y}}=32.81 \mathrm{MPa}$. The distribution of shear stress $\tau_{\mathrm{xy}}$ is symmetrically opposite at the center of the key strata with a value of zero at the center point, and the shear stress is the largest at the center of the four small rectangles (Figure 3(c)), with a maximum value of $2.43 \mathrm{MPa}$. Similarly, the compressive stress reaches a maximum value at the center point of the lower surface of the water-resistant key strata with $\sigma_{\mathrm{x}}=15.08 \mathrm{MPa}$ and $\sigma_{\mathrm{y}}=33.33 \mathrm{MPa}$, which represent magnitudes larger than those of the maximum compressive stress in the upper surface. The compressive stress of the lower surface achieves the maximum value at the center point of the long edge, with $\sigma_{\mathrm{x}}=3.34 \mathrm{MPa}$ and $\sigma_{\mathrm{y}}=22.81 \mathrm{MPa}$, which represent magnitudes smaller than those of the maximum tensile stress on the surface. The shear stress at the same $x$ and $y$ coordinates is the same as that at the upper and lower surfaces of the plate, but in the opposite direction.

The abovementioned analytical results show that the floor key strata produce an upward bending under the combined action of the lower transverse load and longitudinal horizontal geostress, resulting in the pulling of the middle of the upper plate and the boundary region of the lower surface, as well as the pressing of the boundary regions of the upper surface and the central region of the lower plate. According to the results of the elastic mechanics calculation adopted in this paper, compared with the numerical values, the maximum tensile stress is located at the center of the upper surface of the key strata, and the maximum compressive stress is located at the center point of the lower surface. This result indicates that the center point of the key strata is the weak area of water inrush from the floor and should be given more attention. This result is different from the conclusions obtained using fixed beam analysis.

According to the stress distribution law of the key strata and the failure characteristics of rock, two main failure forms occur in the floor key strata under vertical and horizontal loads: (1) shear failure occurs in the compression part of the key strata and (2) tensile failure occurs in the tensile parts. Different applications of force to the key strata of the floor will change the water control strategy of the floor. The expression of the key strata's stress component is deduced in the preceding section, and the corresponding yield criterion can be used to obtain the mechanical evaluation formula for the two failure forms in the key strata.

The former analysis reveals that the maximum compressive stress is at the center point $\left(x=0, y=0, z=h_{\mathrm{k}} / 2\right)$ of the lower surface of the water-resistant key strata. The main stress of this point can be obtained by (9).

$$
\left\{\begin{array}{l}
\sigma_{1}=B q\left(a^{2}+\mu_{k} b^{2}\right)+N, \\
\sigma_{2}=B q\left(b^{2}+\mu_{k} a^{2}\right)+N, \\
\sigma_{3}=0 .
\end{array}\right.
$$

In the formula,

$B=\frac{24 E_{k} a^{2} b^{2}}{E_{k} h_{k}^{3} \pi^{2}\left(a^{4}+b^{4}+(2 / 3) a^{2} b^{2}\right)-3 N h_{k} a^{2} b^{2}\left(1-\mu_{k}^{2}\right)\left(a^{2}+b^{2}\right)}$.

The yield criterion of Mohr-Coulomb is adopted.

$$
\sigma_{1}-\sigma_{3} N_{\varphi k}-2 c_{k} \sqrt{N_{\varphi k}}=0
$$

where $N_{\phi k}=1+\sin \phi_{k} / 1-\sin \phi_{k}$.

According to (11), (12), and (13), the critical water pressure (without shear failure) that occurs at the key strata is

$$
p_{s s}=\frac{2 c_{k} \sqrt{N_{\varphi k}}-N}{B\left(a^{2}+\mu_{k} b^{2}\right)}+\gamma_{k} h_{k}+\gamma_{b} h^{\prime}-\gamma_{b} h_{a}-\gamma_{b} h_{k} .
$$

The maximum tensile stress is located in the center point ( $\left.x=0, y=0, z=-h_{\mathrm{k}} / 2\right)$ of the top surface of the key floor. According to (9), the maximum tensile stress at this point is

$$
\sigma_{3}=-B q\left(a^{2}+\mu_{k} b^{2}\right)+N .
$$

To prevent tensile failure in the key strata, the maximum tensile stress $\left(\sigma_{3}\right)$ should be less than the allowed tensile strength $\left[\sigma_{\mathrm{kt}}\right]$ of the rock, that is, $-\sigma_{3} \leq\left[\sigma_{\mathrm{t}}\right]$. The critical water pressure (without tensile failure) that occurs in the key strata is expressed as follows:

$$
p_{\mathrm{ts}}=\frac{\left[\sigma_{\mathrm{kt}}\right]+N}{B\left(a^{2}+\mu_{k} b^{2}\right)}+\gamma_{k} h_{k}+\gamma_{b} h^{\prime}-\gamma_{b} h_{a}-\gamma_{b} h_{k} .
$$




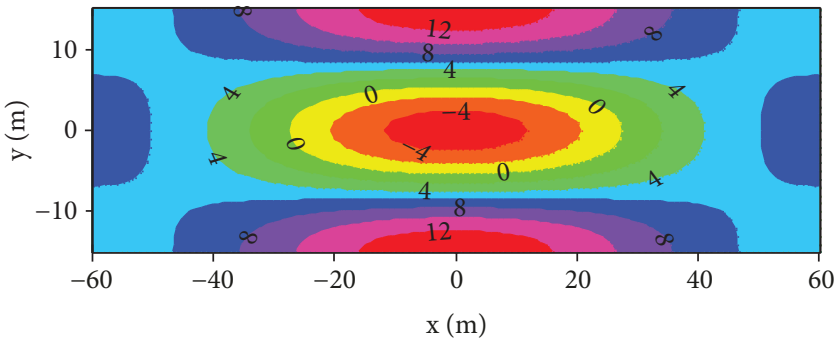

(a)

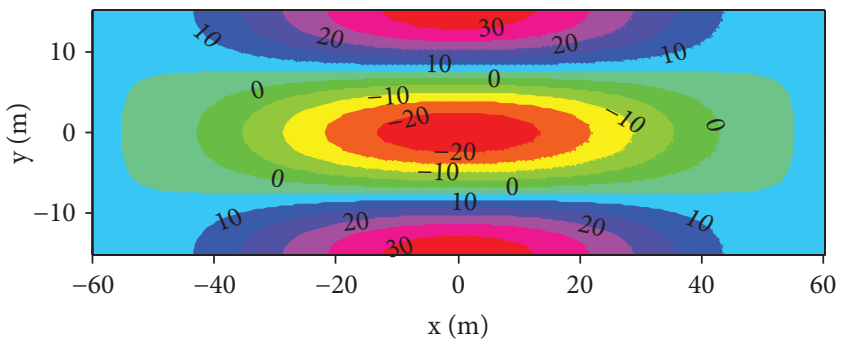

(b)

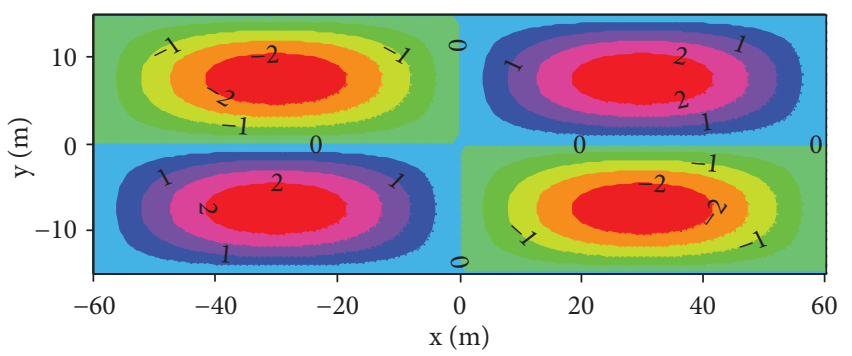

(c)

FIgURE 3: Stress distribution of water-resistant key strata. (a) Distribution diagram of $\sigma_{\mathrm{x}}$. (b) Distribution diagram of $\sigma_{\mathrm{y}}$. (c) Distribution diagram of $\tau_{\mathrm{xy}}$.

\subsection{Reliability Calculation of the Impervious Base Stability.} The reliability calculation of the stability system of the water-resistant floor mainly comes down to two problems: (1) to determine the main failure modes of the waterresistant floor and (2) to calculate the reliability of the stability system of the water-resistant floor.

Structural reliability refers to the probability that the engineering structure will complete the scheduled function within the given time and under the specified conditions [24]. As mentioned above, the two main failure modes of the water-resistant floor that lead to the floor losing its resisting function are as follows:

(1) Under mining influence, the key strata are affected by the mining failure depth of the floor and the intrusion height of the confined water, resulting in the thickness of key strata being zero, that is, the key strata are water-resistant. The failure modes can be divided into three subfailure modes in this case. The first is when the mining failure depth of $h_{\mathrm{a}}$ reaches the bottom of the key strata, that is, $h_{\mathrm{a}} \geq h^{\prime}$; this is known as the failure mode of the mining failure type. The second is when the intrusion height $h_{c}$ of the confined water reaches the top of the water-resistant key strata, that is, $h_{\mathrm{c}} \geq h-h_{\mathrm{c}}+h_{\mathrm{k}}$; this is known as the failure mode of the intrusion type. The third is when $h_{\mathrm{a}}<$ $h^{\prime}$ and $h_{\mathrm{c}}<h-h_{\mathrm{c}}+h_{\mathrm{k}}$, and the mining failure belt of the floor comes in contact with the intrusion zone of the confined water, that is, $h_{\mathrm{a}}+h_{\mathrm{c}} \geq h$; this is called the failure mode of the combined type of mining failure and intrusion

(2) When the thickness of the floor key strata satisfies $h_{\mathrm{k}}>0$, the floor failure is mainly caused by the insufficient strength of the key strata itself. The failure of the key strata can be divided into two modes: shear and tensile failure types. Figure 4 summarizes the various failure modes of the waterresistant floor

Let $X=\left(X_{1}, X_{2}, X_{3}, \ldots, X_{\mathrm{n}}\right)$ represent the basic random variables of the number of factors $n$ that affect the waterresisting function of the floor, such as rock mass parameters, failure depth of the floor $\left(h_{\mathrm{a}}\right)$, intrusion height of the confined water $\left(h_{\mathrm{c}}\right), N$, and lateral pressure coefficient $k_{0}$. When the general load-resistance $(R-S)$ mode is used, the performance function of each failure mode can be listed as given below.

The performance functions of the failure mode of mining failure and intrusion type are as follows:

$$
\begin{aligned}
& Z_{11}=g(X)=h^{\prime}-\frac{1.57 \gamma^{\prime 2} H^{2} a(1-\sin \varphi)^{2}}{16 c^{2} \cos ^{2} \varphi}, \\
& Z_{12}=g(X)=h-h_{c}-h^{\prime}+h_{k} .
\end{aligned}
$$

When $Z_{11}>0$ and $Z_{12}>0$, the floor is in a reliable state. When $Z_{11}<0$ and $Z_{12}<0$, the water-resistant layer fails. When $Z_{11}=Z_{12}=0$, the resulting expression is called the limit state equation of the floor structure. According to the calculation method of reliability, the failure probability in different failure modes can be obtained as follows:

$$
\begin{aligned}
& P_{\mathrm{f} 11}=P\left(Z_{11} \leq 0\right), \\
& P_{\mathrm{f} 12}=P\left(Z_{12} \leq 0\right) .
\end{aligned}
$$




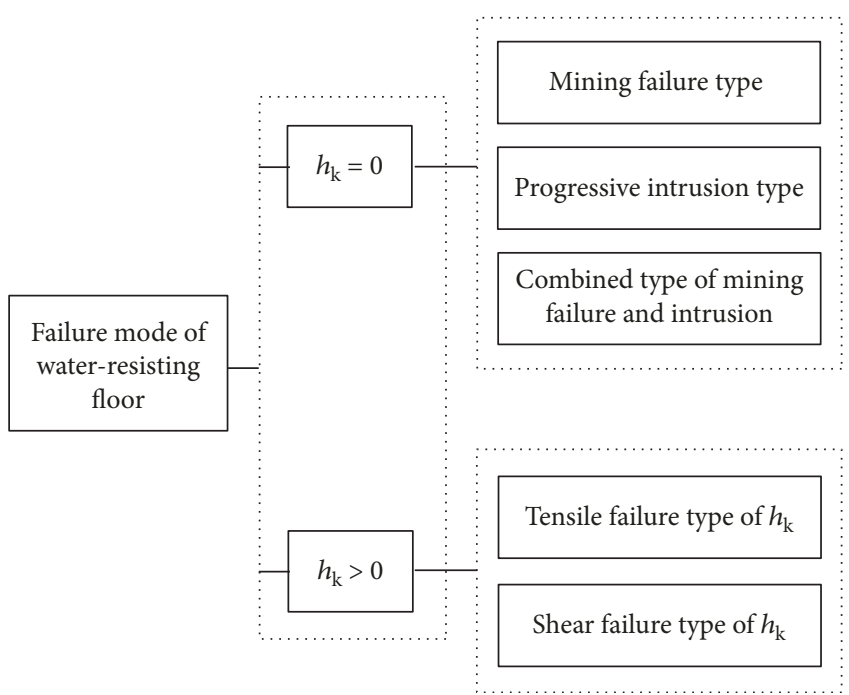

Figure 4: Main failure mode of the water-resistant floor.

Then, the reliability probabilities of the failure modes are as follows:

$$
\begin{aligned}
& P_{\mathrm{r} 11}=1-P_{\mathrm{f} 11}, \\
& P_{\mathrm{r} 12}=1-P_{\mathrm{f} 12} .
\end{aligned}
$$

Similarly, the performance function of the combined failure mode of mining failure and intrusion is

$$
Z_{13}=g(X)=h-\frac{1.57 \gamma^{\prime 2} H^{2} a(1-\sin \varphi)^{2}}{16 c^{2} \cos ^{2} \varphi}-h_{c}
$$

The failure mode of the combined type of mining failure and intrusion is likely to occur when both failure modes do not occur. Therefore, failure probability can be calculated under the conditions of $Z_{11}>0$ and $Z_{12}>0$, making it a conditional probability. Hence, the failure probability of failure modes, which is the combined type of mining failure and intrusion, is as follows:

$$
P_{\mathrm{f} 13}=P\left(Z_{13}<0 \mid Z_{11}>0, Z_{12}>0\right) .
$$

Similarly, the reliability probability of the floor is

$$
P_{\mathrm{r} 13}=1-P_{\mathrm{f} 13}
$$

When the thickness of the floor's key strata is not zero, the failure of the key strata is mainly caused by the lack of strength in the key strata. The performance function of shear failure is

$$
Z_{2 s}=\frac{2 c_{k} \sqrt{N_{\varphi k}}-N}{B\left(a^{2}+\mu_{k} b^{2}\right)}+\gamma_{k} h_{k}+\gamma_{b} h^{\prime}-\gamma_{b} h_{a}-\gamma_{b} h_{k}-p .
$$

The function of tensile failure is

$$
Z_{2 t}=\frac{\left[\sigma_{k t}\right]+N}{B\left(a^{2}+\mu_{k} b^{2}\right)}+\gamma_{k} h_{k}+\gamma_{b} h^{\prime}-\gamma_{b} h_{a}-\gamma_{b} h_{k}-p .
$$

Similarly, the failure mode of shear or tensile failure in the key strata is likely to occur in the case of $h_{\mathrm{k}} \neq 0$, and the failure probability of the failure mode is also a conditional probability. The failure probability is shown below.

The failure mode of shear failure is

$$
P_{\mathrm{f} 2 \mathrm{~s}}=P\left(Z_{2 \mathrm{~s}}<0 \mid Z_{11}>0, Z_{12}>0, Z_{13}>0\right) .
$$

The failure mode of tensile failure is

$$
P_{\mathrm{f} 2 \mathrm{t}}=P\left(Z_{2 t}<0 \mid Z_{11}>0, Z_{12}>0, Z_{13}>0\right) .
$$

Similarly, the reliability probability that prevents the key strata from experiencing shear or tensile failure modes is as follows:

For no occurrence of shear failure,

$$
P_{\text {r2j }}=1-P_{\text {f2s }} .
$$

For no occurrence of tensile failure,

$$
P_{\text {r2t }}=1-P_{\text {f } 2 \mathrm{t}}
$$

The methods for calculating reliability include analytical and simulation methods. The first-order second-moment method is widely used as an analytic method. The most popular simulation method is the Monte Carlo method, which is considered a relatively accurate current method in the calculation of reliability. Considering the complexity of the limit state equation of various failure modes in the floor water inrush deduced in this study, calculating the derivative is difficult when analytical methods are used. Thus, the Monte Carlo method is adopted for reliability calculation. The basic principle of this calculation is as follows.

The density function of joint probability of basic random variables $X=\left(X_{1}, X_{2}, X_{3}, \ldots, X_{\mathrm{n}}\right)$ is set as $f_{X}(x)=$ $f_{X}\left(x_{1}, x_{2}, \ldots, x_{n}\right)$, such that the failure probability of floor structure is

$$
\begin{aligned}
P_{\mathrm{f}} & =\int_{\cdots} \ldots \int{ }_{Z \leq 0} f_{X}\left(x_{1}, x_{2}, \ldots, x_{\mathrm{n}}\right) d x_{1} d x_{2} \cdots d x_{\mathrm{n}} \\
& =\int_{-\infty}^{+\infty} I\left[g_{X}(x)\right] f_{X}(x) d x=E\left\{I\left[g_{X}(x)\right]\right\},
\end{aligned}
$$

where $I(x)$ is the indicating function of $x$. When $x<0$, $I(x)=1$, and when $x \geq 0, I(x)=0$ [25].

Equation (32) shows that the failure probability is the expected value of the indicating function. Different values of $I(x)$ are obtained using the Monte Carlo method to perform bulk sampling of random variables $X_{1}, X_{2}, X_{3}, \ldots, X_{\mathrm{n}}$, and the mean value is the estimated value of the floor failure probability. On the basis of the various performance 
functions of the floor failure, the failure probability and reliability probability of each failure mode can be calculated by using the Monte Carlo method.

The system reliability is a structural reliability problem for multiple performance functions. A single structural failure is mostly caused by various failure modes. When any failure mode occurs, overall structural damage occurs, and the structural system can be regarded as a series system composed of various failure modes; when all failure modes occur with structural damage, the structural system can be regarded as a parallel system. Previous analysis has indicated that the occurrence of any failure mode of the water-resistant floor will lead to the occurrence of water inrush. Hence, the structural system is a series system.

The failure probability of a series system is the sum of each failure mode. The performance function of the $i$ th failure mode in a series system is set as $Z_{\mathrm{i}}=g X_{\mathrm{i}}(x)$, and the formula of failure probability of a series system is

$$
\begin{aligned}
P_{\mathrm{f}} & =P\left(\bigcup_{i=1}^{m} Z_{i} \leq 0\right)=\int \bigcup_{i=1}^{m} Z_{i} \leq 0 \\
& f_{X}(x) d x \\
& =\int \cdots \int \bigcup_{i=1}^{m} Z_{i} \leq 0 \\
f_{X} & \left(x_{1}, x_{2}, \cdots, x_{\mathrm{n}}\right) d x_{1} d x_{2} \cdots d x_{\mathrm{n}}
\end{aligned}
$$

When the failure probability of the series system is calculated by the Monte Carlo method using (33), according to (32), the indicating function of the series system becomes [25]

$$
I\left[g_{X}(x)\right]=\prod_{i=1}^{m} I\left[g_{X i}(x)\right]=I\left[\min _{1 \leq i \leq m} g_{X i}(x)\right]
$$

The reliability probability of the system with a stable water-resistant floor is calculated by the method used to calculate the reliability probability of the single failure mode according to (34).

\section{Results and Discussion}

Given the width of the working face $a=120 \mathrm{~m}, b$ is the initial roof weight step for the working face, which is $40 \mathrm{~m}$; the cover depth of the coal seam is $H=600 \mathrm{~m}$, the water pressure of the confined aquifer is $p=2.5 \mathrm{MPa}$, the total thickness of the water-resistant floor is $h=45 \mathrm{~m}$, the thickness of the key strata is $h_{\mathrm{k}}=8 \mathrm{~m}$, and the distance from its bottom to the coal seam floor is $35 \mathrm{~m}$. The basic random variables are listed in Table 1. Poisson's ratio $(\mu)$ of the rock and soil mass and the weight $\gamma$ changed only slightly and they can thus be regarded as constants, with the following values used for the calculation: $\mu_{\mathrm{k}}=0.26, \gamma^{\prime}=23 \mathrm{kN} / \mathrm{m}^{3}, \quad \gamma_{\mathrm{a}}=\gamma_{\mathrm{b}}=26 \mathrm{kN} / \mathrm{m}^{3}$, and $\gamma_{\mathrm{k}}=28.5 \mathrm{kN} / \mathrm{m}^{3}$. All the random variables follow a normal distribution regardless of the correlation between the parameters, and the number of samplings in the calculation of reliability probability is 1 million times. In the program, the values of $h_{\mathrm{a}}$ and $h_{\mathrm{c}}$ calculated from each sampling are applied to the water-resistant key strata to determine if $h_{\mathrm{k}}$ needs to be changed.

3.1. Effects of Random Variables on Stable Reliability Probability. The reliability probability of each failure mode is studied by changing the mean value of a single random variable. Figures 5 and 6 , respectively, show the results when the average cohesive force $c$ of the floor and the coefficient of horizontal pressure $k_{0}$ are taken as example variables.

From the former analysis, the random variable $c$ affects the value of the mining failure depth $h_{\mathrm{a}}$ of the floor and influences the actual thickness of the key strata through $h_{\mathrm{a}}$. The reliability probability of the failure modes of floor mining failure type, the combined intrusion and mining failure, and the shear and tensile failure modes of key strata are all affected by the change mean of $c$ (Figure 5). However, when $c$ is higher than $6 \mathrm{MPa}$, the elevated level of each failure mode and the reliability probability of system delay obviously increases with the increase in the mean of $c$. This phenomenon shows that when the strength of the water-resistant floor reaches a certain value, it cannot effectively improve the reliability probability of the stability of the water-resistant floor by continually improving the floor strength. The failure mode of the intrusion type is not affected by the random variable $c$, and the reliability probability is stable at approximately 0.99998 (Figure 5(a)).

In this study, the random variable $k_{0}$ affects the occurrence probability of the failure mode of shear and tensile failure in the key strata and the system. Figure 6 shows that the reliability probability of the shear failure mode of the key strata decreases with the increase in the mean of $k_{0}$, while the reliability probability of tensile failure mode increases. When the lateral pressure coefficient $k_{0}$ is smaller, that is, the horizontal stress is smaller, the tensile failure of the key strata is more likely to occur than the shear failure. With the increase in geostress, the tensile stress produced by the transverse bending is offset, in part owing to the existence of the horizontal compressive stress; therefore, the possibility of tensile stress occurring at the key strata decreases, while the possibility of shear failure increases. When the horizontal stress increases to a certain extent (such as 1.5), the possibility of occurrence of shear failure exceeds that of the tensile failure type. At this instant, the system reliability probability reaches the maximum value of 0.96359 . Later, with the increase in the mean value of $k_{0}$, the reliability probability of the system decreases continuously.

In addition, the reliability probabilities of the above failure modes are basically stable at approximately 0.99818 , 0.99998, and 0.99994, owing to the mining failure type of the floor, and the intrusion type and the combined failure mode of the two are independent of $k_{0}$.

3.2. Effects of Variation Coefficients on Stable Reliability Probability. Changing the variation coefficient value of the single random variable enables the study of the reliability probability of each failure mode. Figure 7 shows the results when the average cohesive force $c$ of the floor and the intrusion height of the confined water $h_{\mathrm{c}}$ are taken as examples. 
TABLE 1: Statistics of the random variables in the synthetic case.

\begin{tabular}{lcccccccc}
\hline Parameters & $\sigma_{\mathrm{kt}} / \mathrm{MPa}$ & $c_{\mathrm{k}} / \mathrm{MPa}$ & $\varphi_{\mathrm{k}} /\left(^{\circ}\right)$ & $c / \mathrm{MPa}$ & $\varphi /\left(^{\circ}\right)$ & $k_{0}$ & $E_{\mathrm{k}} \mathrm{GPa}$ & $h_{\mathrm{c}}(\mathrm{m})$ \\
\hline$u_{\mathrm{f}}$ & 13.5 & 14 & 38 & 7.0 & 34 & 1.0 & 17 \\
$\sigma_{\mathrm{f}}$ & 0.9 & 1.5 & 3.5 & 0.9 & 2.9 & 0.5 & 1.0 \\
$\delta_{\mathrm{f}}$ & 0.067 & 0.107 & 0.092 & 0.129 & 0.085 & 0.500 & 0.059 & 0.125 \\
\hline
\end{tabular}

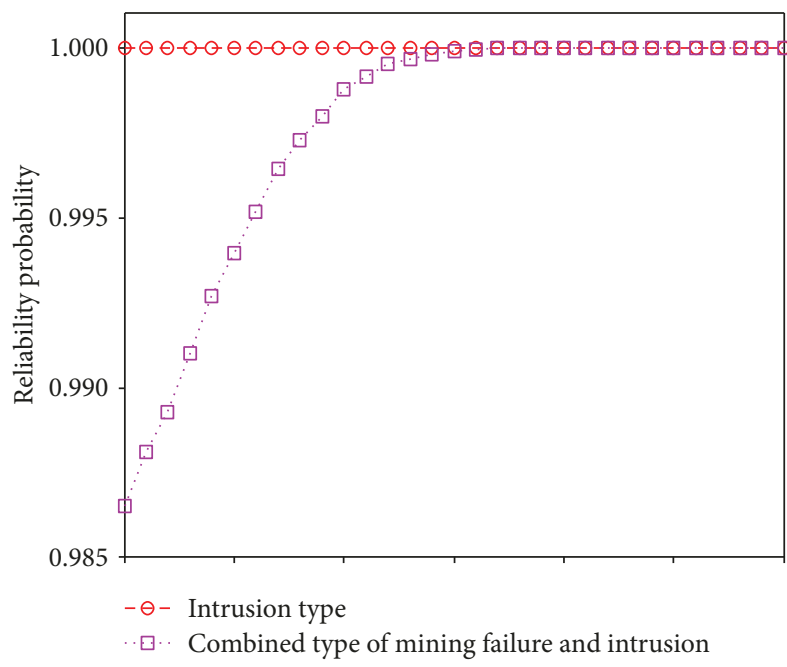

(a)

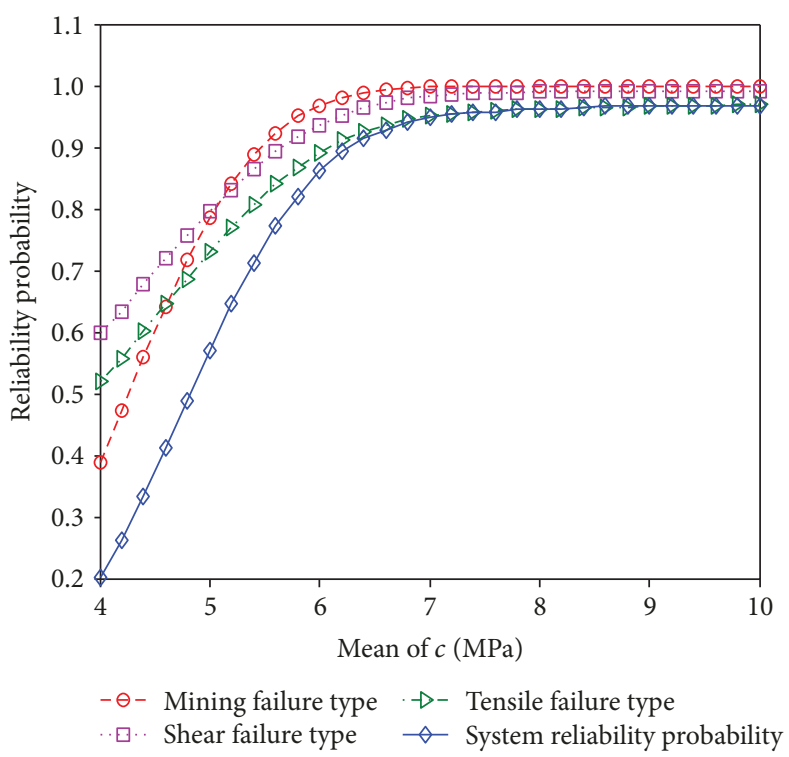

(b)

FIGURE 5: Relationship between the mean value of $c$ and the reliability probability. (a) Failure modes of intrusion type and the combined type of mining failure and intrusion and (b) mode diagram of mining failure, 585 shear and tensile failure in key strata, and system failure.

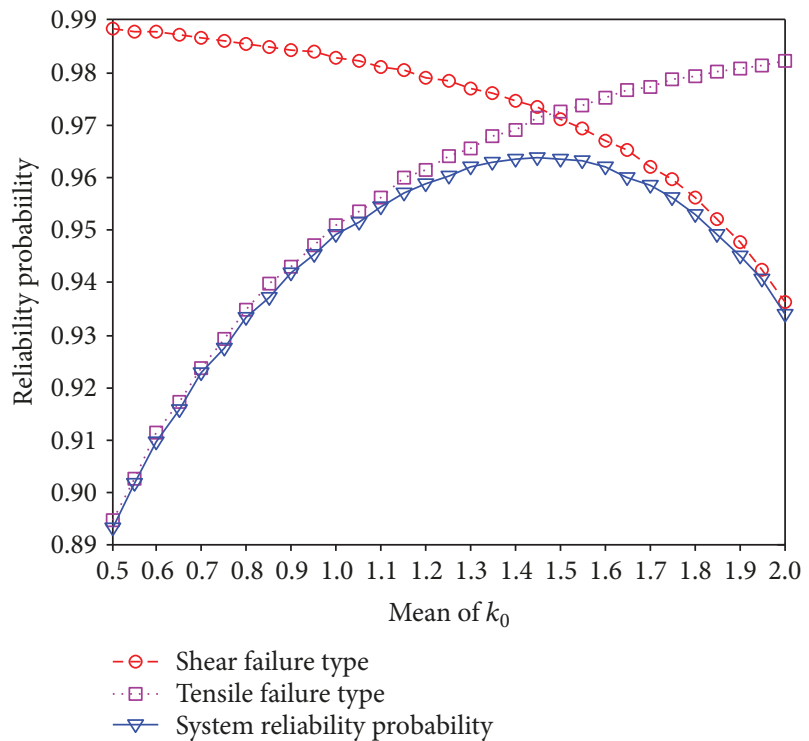

FIgURE 6: Relationship between the mean value of $k 0$ and shear and tensile failure in key strata and the reliability probability of the system.
Figure 7 shows that with the increase in the variation coefficient $c$, the failure modes associated with $c$ and the reliability probability of the system decrease in varying degrees. When the variation coefficient reaches 1.1 , the reliability probability of the system decreases significantly. When the variation coefficient $c$ reaches 2 , the failure modes of the system change from tensile failure type to mining failure. The intrusion failure mode is not affected by random variable $c$, and its reliability probability is basically stable at approximately 0.99998 .

The value of random variable $h_{\mathrm{c}}$ affects the actual thickness value of the key strata, consequently changing the value of variation coefficient $h_{\mathrm{c}}$ and affecting the reliability probability of failure modes of the intrusion type, the combined mining failure and intrusion types, and the shear and tensile failure types in the key strata (Figure 8). Similarly, as the variation coefficient $h_{c}$ increases, the relevance of each failure mode and the reliability probability of the system are reduced to different degrees. The reliability probability decreases in a pronounced manner when the variation coefficient reaches 2.6. The tensile failure mode is always the main failure mode of the water-resistant floor system, as shown by the analysis of the reliability probability of the system. The mining failure is not affected by random variable $h_{c}$, and thus, its reliability probability is basically stable at approximately 0.99818 . 


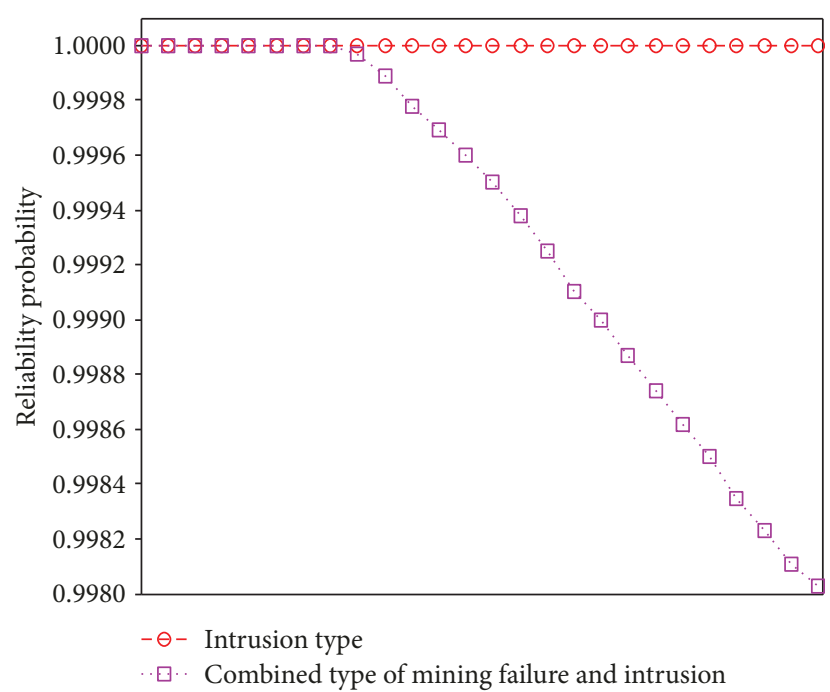

(a)

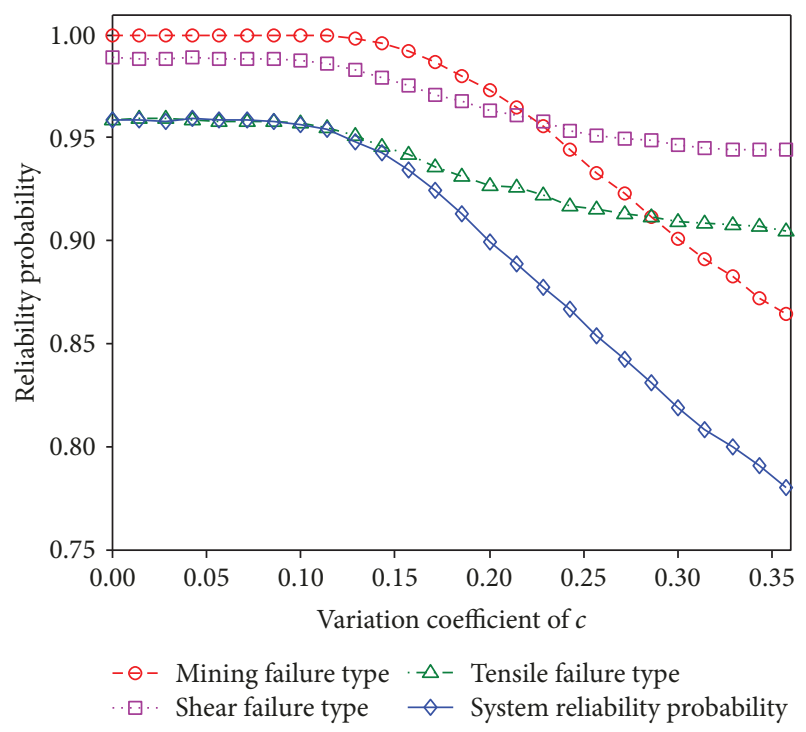

(b)

FIGURE 7: Relationship between variation coefficient of random variables $c$ and reliability probability. (a) Failure modes of intrusion type and the combined type of mining failure and intrusion and (b) mode of mining failure, shear and tensile failure in key strata, and system failure.

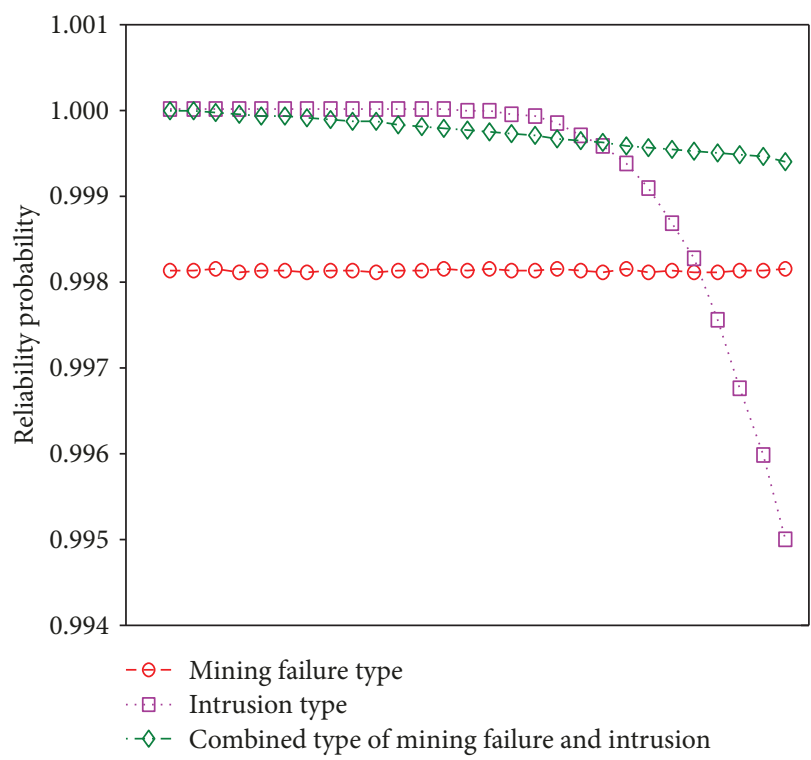

(a)

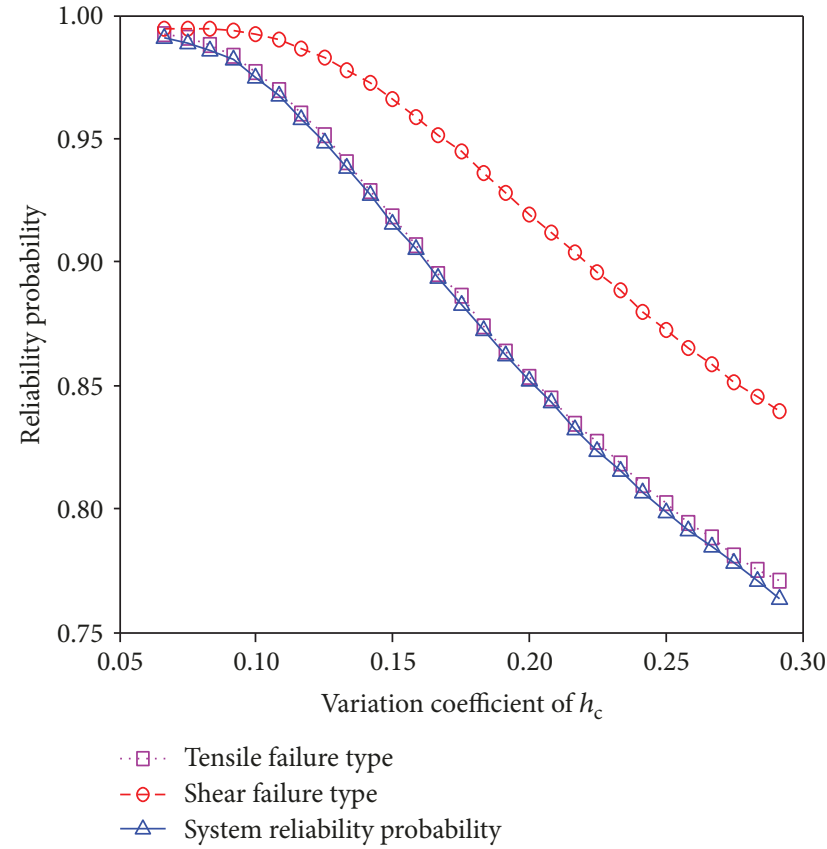

(b)

FIGURE 8: Relationship between variation coefficient of random variables $h \mathrm{c}$ and reliability probability. (a) Failure modes of mining failure, intrusion, and the combination mining failure and intrusion and (b) modes of shear, tensile failure in key strata, and system failure.

The above analysis shows that the variation coefficient of random variables is inversely proportional to the stability probability of the water-resistant floor. The reliability probability of various failure modes and the system reliability probability decrease with the increase in the variation coefficient. The impact of the variation coefficient on the water-resistant floor stability is significant.
In the first failure mode, $K_{1}=h^{\prime} / h_{\mathrm{a}}, K_{2}=\left(h-h^{\prime}+h_{\mathrm{k}}\right) / h_{\mathrm{c}}$, and $K_{1}=h /\left(h_{\mathrm{a}}+h_{\mathrm{c}}\right)$ are defined as the safety factors of the failure modes of the mining failure type, the intrusion type, and the combination of the two, respectively. Correspondingly, in the second main failure mode, the safety factor is defined by the ratio of the critical water pressure of (7) and (9) to the actual water pressure under the shear and tensile 
TABLE 2: Calculation results of the median safety factor of stability of the water-resistant floor.

\begin{tabular}{|c|c|c|c|c|c|}
\hline \multirow{2}{*}{ Parameter } & \multicolumn{3}{|r|}{ First type of failure mode } & \multicolumn{2}{|c|}{ Second type of failure mode } \\
\hline & Mining failure & Intrusion & Combined mode involving mining and intrusion & Tensile failure & Shear failure \\
\hline Median safety factor of $K$ & 2.705 & 1.750 & 1.925 & 1.744 & 2.645 \\
\hline
\end{tabular}

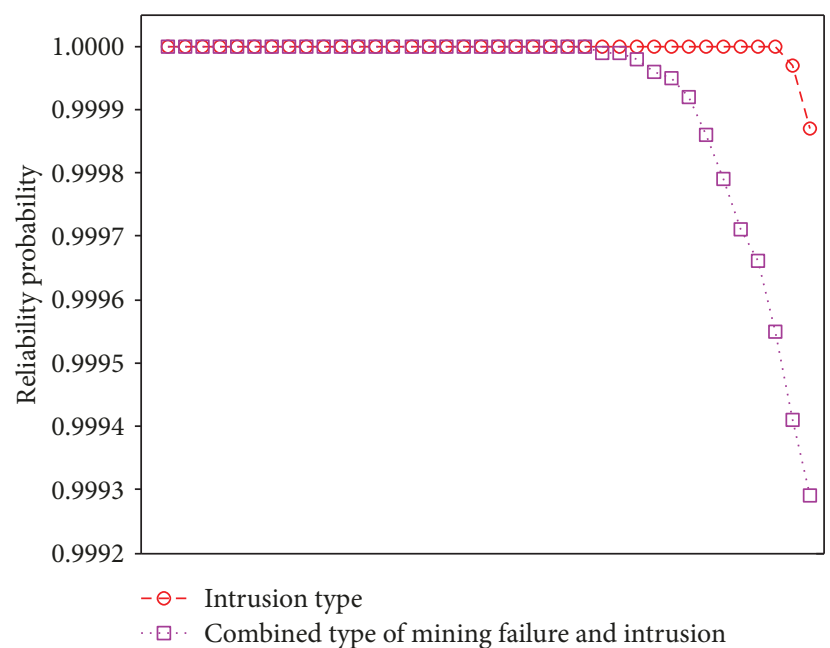

(a)

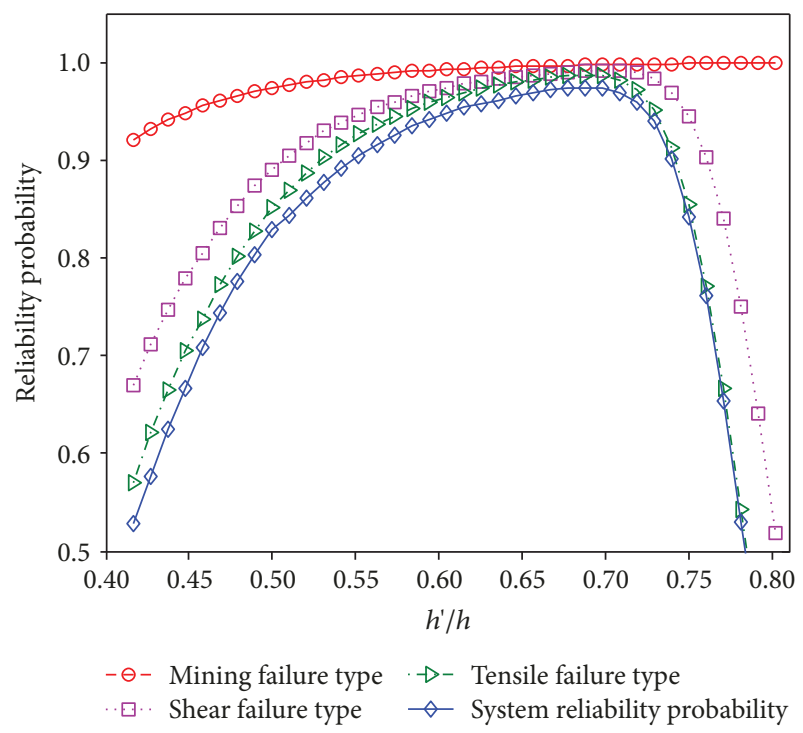

(b)

FIGURE 9: Relationship between the position of key strata and reliability probability. (a) Failure modes of intrusion type and the combined type of mining failure and intrusion and (b) mining failure, shear and tensile failure of key strata, and failure mode of the system.

failures of the key strata. The safety factor is calculated using the mean values of the random variables listed in Table 1, that is, the median safety factor. The calculation results are presented in Table 2.

Table 2 shows that when the safety factor is used to evaluate the stability of the water-resistant floor, the value is only affected by the mean of the variables. The physical and mechanical parameters of the rock mass and the randomness of the load are not fully considered. Figures 7 and 8 show that the coefficient of variation increases and the probability of reliability decreases under the same safety factor. When the safety factor is large, the reliability probability of the floor is still relatively low. Therefore, the stability of the floor cannot be guaranteed solely by the safety factor. The use of reliability theory is more objective and reasonable for studying the stability of the water-resistant floor.

\subsection{Effects of Key Strata Locations on Stability Reliability} Probability. To analyze the influence of the key strata position on the stability and reliability probability of the floor, the probability of each failure mode under different ratios can be calculated by choosing different ratios of $h^{\prime}$ to $h$. The result is shown in Figure 9, which reveals that with the increase in the ratio, that is, when the key strata are far from the coal seam and the influence of mining is reduced, the reliability probability of the failure mode of mining failure type gradually increases. The reliability probability of the failure mode of the intrusion type and the combined type gradually decreases from a constant state, which indicates that the key strata are gradually affected by the intrusion of confined water. The shear and tensile failure modes of the key strata and the reliability probability of the system first increase and later decrease and reach the peak value when the ratio of $h^{\prime}$ to $h$ is approximately 0.7 . The above findings indicate that the position of the key strata significantly influences the stability and reliability probability of the water-resistant floor; when the key strata are far from the influence range of mining and the intrusion of confined water, the stability and reliability probability of the water-resistant floor can reach the maximum value.

\section{Application}

The research results are applied to the mining of a 10-coal seam in the 103rd mining area of the Yangliu mine. The Yangliu mine is located in Suzhou City, Anhui Province, China. The 103rd mining area is located in the middle of the mine. The cover depth of the 10 -coal seam is $500-650 \mathrm{~m}$, and it is a monoclinic structure that tilts to the east. The ground elevation is $+25 \mathrm{~m}$, the distance from the top of the limestone aquifer in Taiyuan formation is $45 \mathrm{~m}$ (i.e., the total thickness of the water-resistant floor is $h=45 \mathrm{~m}$ ), and the lithology of the stratum is dense with mainly mudstone, siltstone, and fine sandstone (Figure 10). According to the results of the 


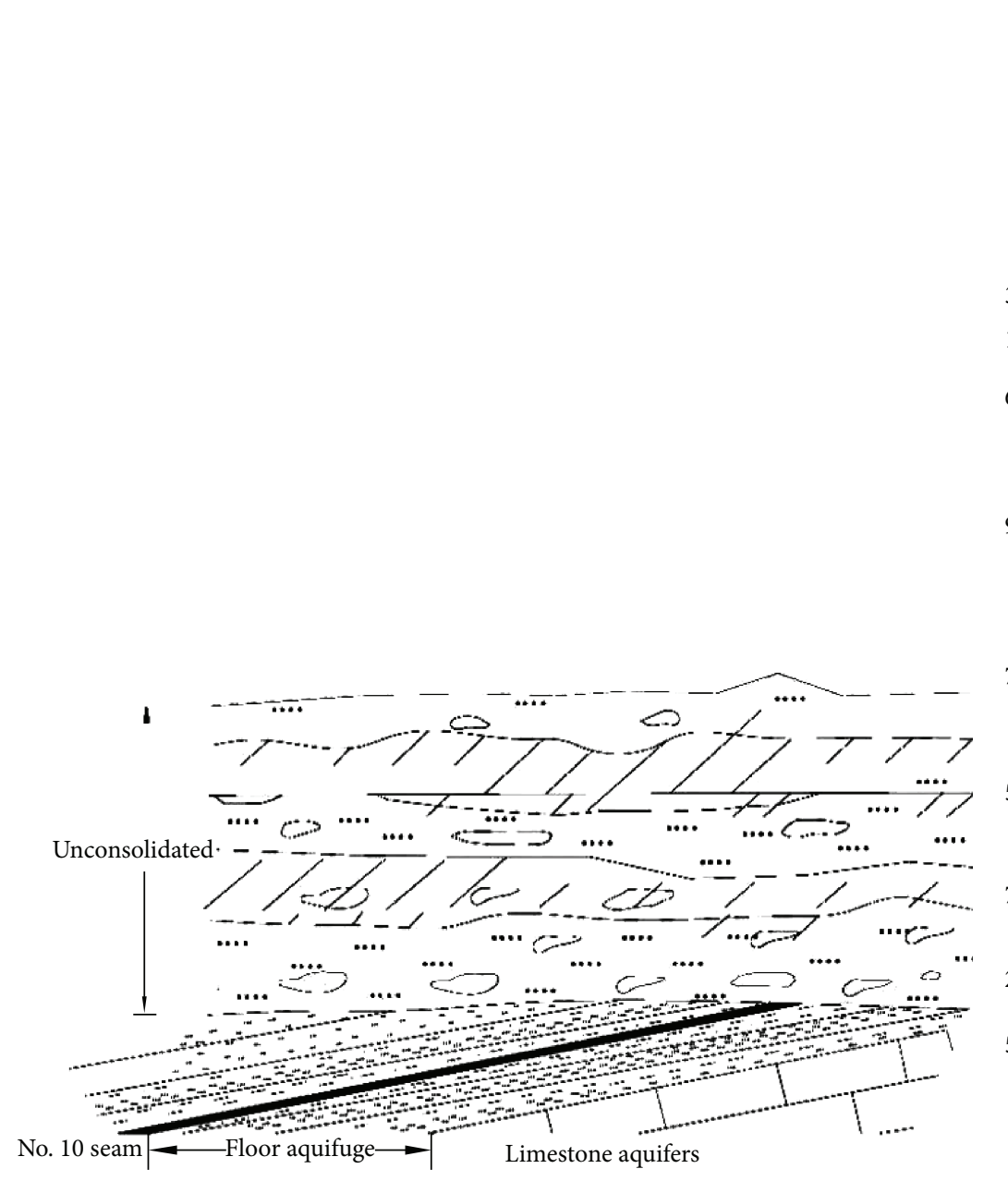

(a)

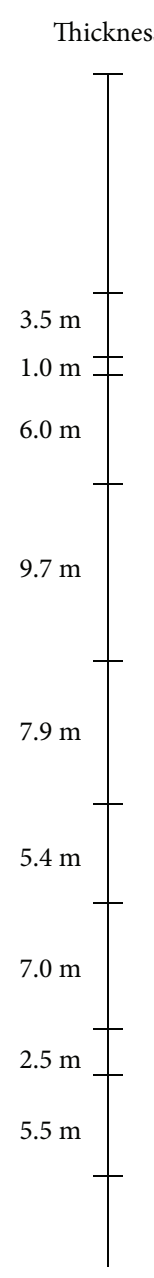

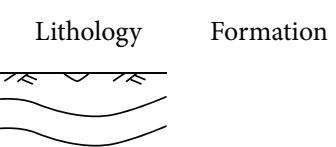

Overburden

No. 10 seam

Mudstone

Siltstone

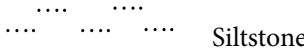

$\cdots+\cdots$
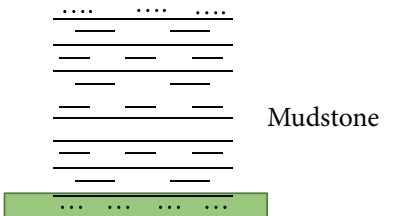

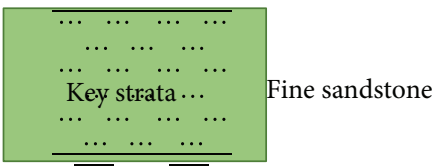

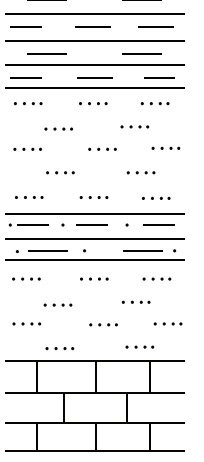

(b)

Mudstone

Siltstone

Sandy mudstone

Siltstone

Limestone

FIGURE 10: Sketch map of the 10-coal seam profile and histogram of the water-resistant floor. (a) Sketch map of the 10-coal seam profile and (b) histogram of the water-resistant floor.

limestone pumping test in the Taiyuan formation in the mining area, the cover depth of static water level of the limestone aquifer is $-38 \mathrm{~m}$, the unit water inflow is $q=0.0855 \mathrm{~L} /(\mathrm{s} \cdot \mathrm{m})$, and the water richness is weak. However, the limestone fracture develops heterogeneity and the local water-rich differences are large, which indicates a potential water risk to the safe mining of the 10-coal seam. Mining began to drain the limestone water in the mining area in 2014. The current cover depth of limestone is $340 \mathrm{~m}$ according to the latest observation results after the dewatering test.

The lithological analysis of the floor water-resistant layer shows that a fine sand layer $7.9 \mathrm{~m}$ thick appears $24.6 \mathrm{~m}$ below the coal seam with a stable distribution. Hence, the rock layer can be considered a water-resistant key stratum, that is, $h_{\mathrm{k}}=7.9 \mathrm{~m}$. The mine pressure monitoring shows that the roof weighting step of the working face in this mine is $40 \mathrm{~m}$.

The height of progressive intrusion in the floor confined water is large in the structural fracture zone and small in the weak area of fracture development. According to the statistical detection data on the mining area for years, the mean value of $h_{c}$ is $12 \mathrm{~m}$, the standard deviation is $2.1 \mathrm{~m}$, and the coefficient of variation is larger at 0.18 . The mean value of the lateral pressure coefficient $k_{0}$ is 1.2 , the standard deviation is 0.08 , and the variation coefficient is not large at 0.07 .

When calculating the depth of the floor mining failure, the mean and standard deviations of the physical and mechanical parameters of the floor rock mass are calculated using (35).

$$
\begin{gathered}
u_{\mathrm{f}}=\frac{\sum_{i=1}^{n} h_{i} u_{\mathrm{f} i}}{\sum_{i=1}^{n} h_{i}}, \\
\sigma_{\mathrm{f}}=\frac{\sum_{i=1}^{n} h_{i} \sigma_{\mathrm{f} i}}{\sum_{i=1}^{n} h_{i}} .
\end{gathered}
$$

In the formula, $h_{\mathrm{i}}$ is the $i$ th layered thickness of the floor, $u_{\mathrm{fi}}$ is the mean of the mechanical parameters of the $i$ th layer, and $\sigma_{\mathrm{fi}}$ is the standard deviation of the mechanical parameters of the $i$ th layer. 
TABLE 3: Statistics of random variables in Yangliu mine.

\begin{tabular}{lcccccccc}
\hline Parameters & $\sigma_{\mathrm{kt}} / \mathrm{MPa}$ & $c_{\mathrm{k}} / \mathrm{MPa}$ & $\varphi_{\mathrm{k}} /\left(^{\circ}\right)$ & $c / \mathrm{MPa}$ & $\varphi /\left(^{\circ}\right)$ & $E_{\mathrm{k}} \mathrm{GPa}$ & $k_{0}$ & $h_{\mathrm{c}}(\mathrm{m})$ \\
\hline$u_{\mathrm{f}}$ & 13.90 & 16.00 & 38.00 & 11.90 & 34.00 & 18.00 & 1.20 \\
$\sigma_{\mathrm{f}}$ & 0.80 & 1.50 & 3.50 & 2.20 & 3.70 & 1.10 & 0.08 \\
$\delta_{\mathrm{f}}$ & 0.06 & 0.09 & 0.09 & 0.19 & 0.11 & 0.06 & 0.07 & 0.18 \\
\hline
\end{tabular}

Table 3 lists the characteristic values of the random variables of rock parameters after the conversion of (35) according to the test data of the physical and mechanical properties of rock in the laboratory. Poisson's ratio and the weight with a subtle change are also considered as constants in the calculation by taking $\mu_{\mathrm{k}}=0.26, \gamma^{\prime}=23 \mathrm{kN} / \mathrm{m}^{3}, \gamma_{\mathrm{a}}=\gamma_{\mathrm{b}}=26 \mathrm{kN} /$ $\mathrm{m}^{3}$, and $\gamma_{\mathrm{k}}=28.5 \mathrm{kN} / \mathrm{m}^{3}$. The various random variables in Table 3 are subjected to a normal distribution, without considering the correlation among the parameters in the calculation process.

According to the cover depth of the 10-coal seam floor, the reliability probability is calculated from the depth of 500-630 m, as given in Table 4 . Table 4 shows that water pressure increases with cover depth, while the safety factor of the mean value and the reliability probability in various failure modes of the floor decrease and the failure probability increases.

Field technicians and mine staff often use the water inrush coefficient method. This method was defined by the Coal Mine Water Prevention and Control Regulations (2009) using the following mathematical expression:

$$
T=\frac{p}{M}
$$

where $T$ is the water inrush coefficient, $\mathrm{MPa} / \mathrm{m} ; \mathrm{p}$ is the water pressure in the floor water-resistant layer, $\mathrm{MPa}$; and $M$ is the total thickness of the floor water-resistant layer, $\mathrm{m}$.

According to the water control requirements of coal mines in China and combined with the actual geological conditions of Huaibei mining area, the water inrush coefficient of the entire floor does not exceed $0.06 \mathrm{MPa} / \mathrm{m}$. Utilizing this method helps determine the maximum safe mining depth of this mining area to be $610 \mathrm{~m}$. However, the calculation results (Table 4) show that the median safety factor of various failure modes is larger when the mining depth is $610 \mathrm{~m}$. Furthermore, the reliability probability of the floor is only $84.5 \%$, and the failure probability is as high as $15.5 \%$. The reliability probability is much lower than those reported in previous research in the literature [26]; specifically, the reliability probability of roadway construction should not be less than $90 \%$. The above calculation shows that if the water inrush coefficient in the traditional fixed-value method is adopted and the maximum mining depth of the 10 -coal seam is determined by the safety coefficient, then water inrush from the floor occurs easily under unfavorable external factors. Therefore, it is not comprehensive and unreliable to determine the risk of water inrush from the floor using only the fixed-value method. The theory of structural system reliability should be introduced in the risk prediction of water inrush from the floor.

The application of the theory of structural system reliability in the evaluation of the water inrush of the coal mining floor above the confined aquifer is still at the trial stage and needs to be tested further in practice. A reasonable distribution model of uncertain factors, such as rock mass parameters, loads, and model sizes, should be established through the accumulation of a large amount of data for more reliable evaluation results.

\section{Summary and Conclusions}

(1) The change in the mean value of the random variable has an important influence on the water pressure resisting capability of the floor. A larger average value of the floor cohesion force corresponds to a higher probability of reliability. However, when the floor cohesion force reaches a certain value, the stability and reliability probability of the floor cannot be improved effectively. A larger lateral pressure coefficient $k_{0}$ indicates a higher horizontal compressive stress. The reliability probability of the shear failure type of the floor key strata decreases, the reliability probability of the tensile failure type increases, and the reliability probability of the series system initially increases and later decreases. The reliability probability of the system reaches the maximum value when the reliability probability of the shear failure type and the tensile failure mode is the same

(2) A larger variance coefficient of the random variable corresponds to a smaller correlative failure mode and the reliability probability of the system; however, the median safety factor remains unchanged

(3) The position of the key strata has an important influence on the stability and reliability probability of the water-resistant floor. When the key strata are far away from the influence range of the mining and confined water progressive intrusion, the stability and reliability probability of the water-resistant floor can reach the maximum value

(4) The application of the case shows that the safety coefficient specified in the regulation and the system reliability probability calculated by the model in this study can be used as an evaluation index to obtain the evaluation results of the risk of floor water inrush more accurately and comprehensively 
TABLE 4: Calculation results of reliability probability of the water-resistant floor's stability.

\begin{tabular}{|c|c|c|c|c|c|c|c|c|}
\hline \multirow[b]{2}{*}{$\begin{array}{l}\text { Cover } \\
\text { depth/m }\end{array}$} & \multirow[b]{2}{*}{$\begin{array}{c}\text { Water } \\
\text { pressure/MPa }\end{array}$} & \multirow[b]{2}{*}{$\begin{array}{l}\text { Coefficient of water } \\
\text { inrush } /\left(\mathrm{MPa} \cdot \mathrm{m}^{-1}\right)\end{array}$} & \multirow[b]{2}{*}{ Parameter } & \multicolumn{3}{|c|}{ First type of failure mode } & \multicolumn{2}{|c|}{$\begin{array}{l}\text { Second type of } \\
\text { failure mode }\end{array}$} \\
\hline & & & & $\begin{array}{l}\text { Mining } \\
\text { failure }\end{array}$ & Intrusion & $\begin{array}{l}\text { Combined mode } \\
\text { involving mining } \\
\text { and intrusion }\end{array}$ & $\begin{array}{l}\text { Tensile } \\
\text { failure }\end{array}$ & $\begin{array}{l}\text { Shear } \\
\text { failure }\end{array}$ \\
\hline \multirow{3}{*}{500} & \multirow{3}{*}{1.6} & \multirow{3}{*}{0.036} & Median safety factor & 9.64961 & 1.70000 & 2.92816 & 2.76584 & 4.75042 \\
\hline & & & Reliability probability & 0.99991 & 0.99995 & 0.99997 & 0.95363 & 0.98151 \\
\hline & & & $\begin{array}{l}\text { Reliability probability of the } \\
\text { system }\end{array}$ & & & 0.95259 & & \\
\hline \multirow{3}{*}{520} & \multirow{3}{*}{1.8} & \multirow{3}{*}{0.040} & Median safety factor & 8.92160 & 1.7000 & 2.87671 & 2.49447 & 4.17738 \\
\hline & & & Reliability probability & 0.99986 & 0.99995 & 0.99998 & 0.93592 & 0.97427 \\
\hline & & & $\begin{array}{l}\text { Reliability probability of the } \\
\text { system }\end{array}$ & & & 0.93549 & & \\
\hline \multirow{3}{*}{540} & \multirow{3}{*}{2.0} & \multirow{3}{*}{0.044} & Median safety factor & 8.27299 & 1.70000 & 2.82513 & 2.27722 & 3.71882 \\
\hline & & & Reliability probability & 0.99977 & 0.99995 & 0.99998 & 0.91824 & 0.96530 \\
\hline & & & $\begin{array}{l}\text { Reliability probability of the } \\
\text { system }\end{array}$ & & & 0.91750 & & \\
\hline \multirow{3}{*}{550} & \multirow{3}{*}{2.1} & \multirow{3}{*}{0.047} & Median safety factor & 7.97488 & 1.70000 & 2.79933 & 2.18406 & 3.52226 \\
\hline & & & Reliability probability & 0.99966 & 0.99996 & 0.99998 & 0.90659 & 0.95931 \\
\hline & & & $\begin{array}{l}\text { Reliability probability of the } \\
\text { system }\end{array}$ & & & 0.90757 & & \\
\hline \multirow{3}{*}{560} & \multirow{3}{*}{2.2} & \multirow{3}{*}{0.049} & Median safety factor & 7.69261 & 1.70000 & 2.77353 & 2.09933 & 3.34353 \\
\hline & & & Reliability probability & 0.99975 & 0.99996 & 0.99994 & 0.89746 & 0.95426 \\
\hline & & & $\begin{array}{l}\text { Reliability probability of the } \\
\text { system }\end{array}$ & & & 0.89656 & & \\
\hline \multirow{3}{*}{570} & \multirow{3}{*}{2.3} & \multirow{3}{*}{0.051} & Median safety factor & 7.42506 & 1.70000 & 2.74774 & 2.02193 & 3.18032 \\
\hline & & & Reliability probability & 0.99959 & 0.99997 & 0.99998 & 0.88736 & 0.94869 \\
\hline & & & $\begin{array}{l}\text { Reliability probability of the } \\
\text { system }\end{array}$ & & & 0.88614 & & \\
\hline \multirow{3}{*}{580} & \multirow{3}{*}{2.4} & & Median safety factor & 7.17123 & 1.70000 & 2.72199 & 1.95095 & 3.03067 \\
\hline & & 0053 & Reliability probability & 0.99955 & 0.99998 & 0.99994 & 0.87791 & 0.94177 \\
\hline & & & $\begin{array}{l}\text { Reliability probability of the } \\
\text { system }\end{array}$ & & & 0.87619 & & \\
\hline & & & Median safety factor & 6.93020 & 1.70000 & 2.696286 & 1.885618 & 2.8929881 \\
\hline 590 & 2.5 & 0.056 & Reliability probability & 0.99954 & 0.99994 & 0.99994 & 0.86646 & 0.93508 \\
\hline & & & $\begin{array}{l}\text { Reliability probability of the } \\
\text { system }\end{array}$ & & & 0.86549 & & \\
\hline & & & Median safety factor & 6.70112 & 1.70000 & 2.67061 & 1.82528 & 2.76586 \\
\hline 600 & 2.6 & 0.058 & Reliability probability & 0.99941 & 0.99995 & 0.99989 & 0.85676 & 0.92849 \\
\hline & & & $\begin{array}{l}\text { Reliability probability of the } \\
\text { system }\end{array}$ & & & 0.85634 & & \\
\hline & & & Median safety factor & 6.48322 & 1.70000 & 2.64501 & 1.76941 & 2.64812 \\
\hline 610 & 27 & 0060 & Reliability probability & 0.99952 & 0.99994 & 0.99992 & 0.84512 & 0.92143 \\
\hline & & & $\begin{array}{l}\text { Reliability probability of the } \\
\text { system }\end{array}$ & & & 0.84503 & & \\
\hline & & & Median safety factor & 6.27582 & 1.70000 & 2.61951 & 1.71751 & 2.53882 \\
\hline 620 & 28 & 0.062 & Reliability probability & 0.99932 & 0.99993 & 0.99992 & 0.83644 & 0.91408 \\
\hline & & & $\begin{array}{l}\text { Reliability probability of the } \\
\text { system }\end{array}$ & & & 0.83609 & & \\
\hline & & & Median safety factor & 6.07823 & 1.70000 & 2.59411 & 1.66907 & 2.43691 \\
\hline 630 & 2.9 & 0.064 & Reliability probability & 0.99919 & 0.99996 & 0.99989 & 0.82507 & 0.90543 \\
\hline & & & $\begin{array}{l}\text { Reliability probability of the } \\
\text { system }\end{array}$ & & & 0.82411 & & \\
\hline
\end{tabular}




\section{Data Availability}

The data used to support the findings of this study are available from the corresponding author upon request.

\section{Conflicts of Interest}

The authors declare that they have no conflicts of interest.

\section{Acknowledgments}

This study was partially supported by the research grants from the National Natural Science Foundation of China (41472235, 51474008, 41330314, and 41501570), the State Key Laboratory for Coal Resources and Safe Mining, China University of Mining \& Technology (No. SKLCRSM16KFD01), the Natural Science Foundation of Anhui Province (1508085QE89), the University Excellent Youth Talent Projects of Anhui Province (gxyq2017004), the Guangdong Provincial Key Laboratory of Soil and Groundwater Pollution Control (No. 2017B030301012), and State Environmental Protection Key Laboratory of Integrated Surface Water-Groundwater Pollution Control. The data used in this paper can be accessed by contacting the corresponding author directly.

\section{References}

[1] L. Q. Shi, W. F. Gao, J. Han, and X. P. Tan, "A nonlinear risk evaluation method for water inrush through the seam floor," Mine Water and the Environment, vol. 36, no. 4, pp. 597605, 2017.

[2] Q. Wu, Z. L. Fan, Z. W. Zhang, and W. F. Zhou, "Evaluation and zoning of groundwater hazards in Pingshuo no. 1 underground coal mine, Shanxi Province, China," Hydrogeology Journal, vol. 22, no. 7, pp. 1693-1705, 2014.

[3] Q. Wu, X. M. Guo, J. J. Shen, S. Xu, S. Q. Liu, and Y. F. Zeng, "Risk assessment of water inrush from aquifers underlying the Gushuyuan coal mine, China," Mine Water and the Environment, vol. 36, no. 1, pp. 96-103, 2017.

[4] W. Li, Y. Liu, W. Qiao, C. Zhao, D. Yang, and Q. Guo, “An improved vulnerability assessment model for floor water bursting from a confined aquifer based on the water inrush coefficient method," Mine Water and the Environment, vol. 37, no. 1, pp. 196-204, 2018.

[5] W. Qiao, W. P. Li, and C. X. Zhao, "Water inrush coefficient unit-inflow method for water inrush of coal mine floor," Chinese Journal of Rock Mechanics and Engineering, vol. 28, no. 12, pp. 2466-2474, 2009.

[6] L. Q. Shi, "Analysis of the origin of water inrush coefficient and its applicability," Journal of Shandong University of Science and Technology, vol. 31, no. 6, pp. 6-9, 2012.

[7] T. Kostecki and A. J. S. Spearing, "Influence of backfill on coal pillar strength and floor bearing capacity in weak floor conditions in the Illinois Basin," International Journal of Rock Mechanics and Mining Sciences, vol. 76, pp. 55-67, 2015.

[8] J. C. Zhang, "Investigations of water inrushes from aquifers under coal seams," International Journal of Rock Mechanics and Mining Sciences, vol. 42, no. 3, pp. 350-360, 2005.

[9] S.-y. Zhu, Z.-q. Jian, H.-l. Hou, W.-g. Xiao, and P. Yao, “Analytical model and application of stress distribution on mining coal floor," Journal of China University of Mining and Technology, vol. 18, no. 1, pp. 13-17, 2008.

[10] H. Yin, L. Lefticariu, J. Wei, J. Guo, Z. Li, and Y. Guan, "In situ dynamic monitoring of stress revolution with time and space under coal seam floor during longwall mining," Environment and Earth Science, vol. 75, no. 18, p. 1249, 2016.

[11] B. Y. Li, “"Down three zones"in the prediction of water inrush from coalbed floor aquifer-theory, development and application," Journal of Shandong Institute of Mining and Technology, vol. 18, no. 4, pp. 11-18, 1999.

[12] J. Sun, L. G. Wang, and H. Q. Hou, "Application of microseismic monitoring technology in mining engineering," International Journal of Mining Science and Technology, vol. 22, no. 1, pp. 79-83, 2012.

[13] X. X. Miao, H. Pu, and H. B. Bai, "Principle of water-resisting key strata and its application in water-preserved mining," Journal of China University of Mining and Technology, vol. 37, no. 1, pp. 1-4, 2008.

[14] M. G. Qian, X. X. Miao, J. L. Xu, and X. B. Mao, Key Strata Theory in Ground Control, China University of Mining and Technology Press, Xuzhou, 2003.

[15] J. Sun and X. X. Miao, "Water-isolating capacity of an inclined coal seam floor based on the theory of water-resistant key strata," Mine Water and the Environment, vol. 36, no. 2, pp. 310-322, 2017.

[16] J. Sun, Y. Hu, and G. Zhao, "Relationship between water inrush from coal seam floors and main roof weighting," International Journal of Mining Science and Technology, vol. 27, no. 5, pp. 873-881, 2017.

[17] J. Zhang, "The influence of mining height on combinational key stratum breaking length,” Procedia Engineering, vol. 26, pp. 1240-1246, 2011.

[18] W. Du, H. Yang, and X. Jia, "Reliability analysis of the steadiness of impervious base," Journal of Hebei University of Engineering, vol. 25, no. 2, pp. 62-64, 2008.

[19] H. F. Lu, B. Y. Yuan, and D. X. Yao, "Reliability analysis of water inrush from seam floor during mining above the confined aquifer," Hydrogeology \& Engineering Geology, vol. 37, no. 6, pp. 1-5, 2010.

[20] H. F. Lu and D. X. Yao, "Structural system reliability analysis on water inrush risk of seam floor during mining above a confined aquifer," Journal of China University of Mining and Technology, vol. 43, no. 6, pp. 995-1002, 2014.

[21] J. C. Zhang, Y. Z. Zhang, and T. Q. Liu, Rock Mass Permeability and Coal Mine Water Inrush, Geological Publishing House, Beijing, 1997.

[22] S. P. Timoshenko and S. W. Woinowsky-Krieger, Theory of Plates and Shells, McGraw-Hill Press, New York, 1959.

[23] Z. L. Xu, Elasticity Mechanics, Higher Education, Beijing, 2006.

[24] H. A. Jensen, F. Mayorga, and M. A. Valdebenito, "Reliability sensitivity estimation of nonlinear structural systems under stochastic excitation: a simulation-based approach," Computer Methods in Applied Mechanics and Engineering, vol. 289, pp. 1-23, 2015.

[25] J. Li, J. B. Chen, and W. L. Fan, “The equivalent extreme-value event and evaluation of the structural system reliability," Structural Safety, vol. 29, no. 2, pp. 112-131, 2007.

[26] M. C. He and Y. H. Su, "Research on reliability of underground soft rock engineering," Chinese Journal of Geotechnical Engineering, vol. 25, no. 1, pp. 55-57, 2003. 

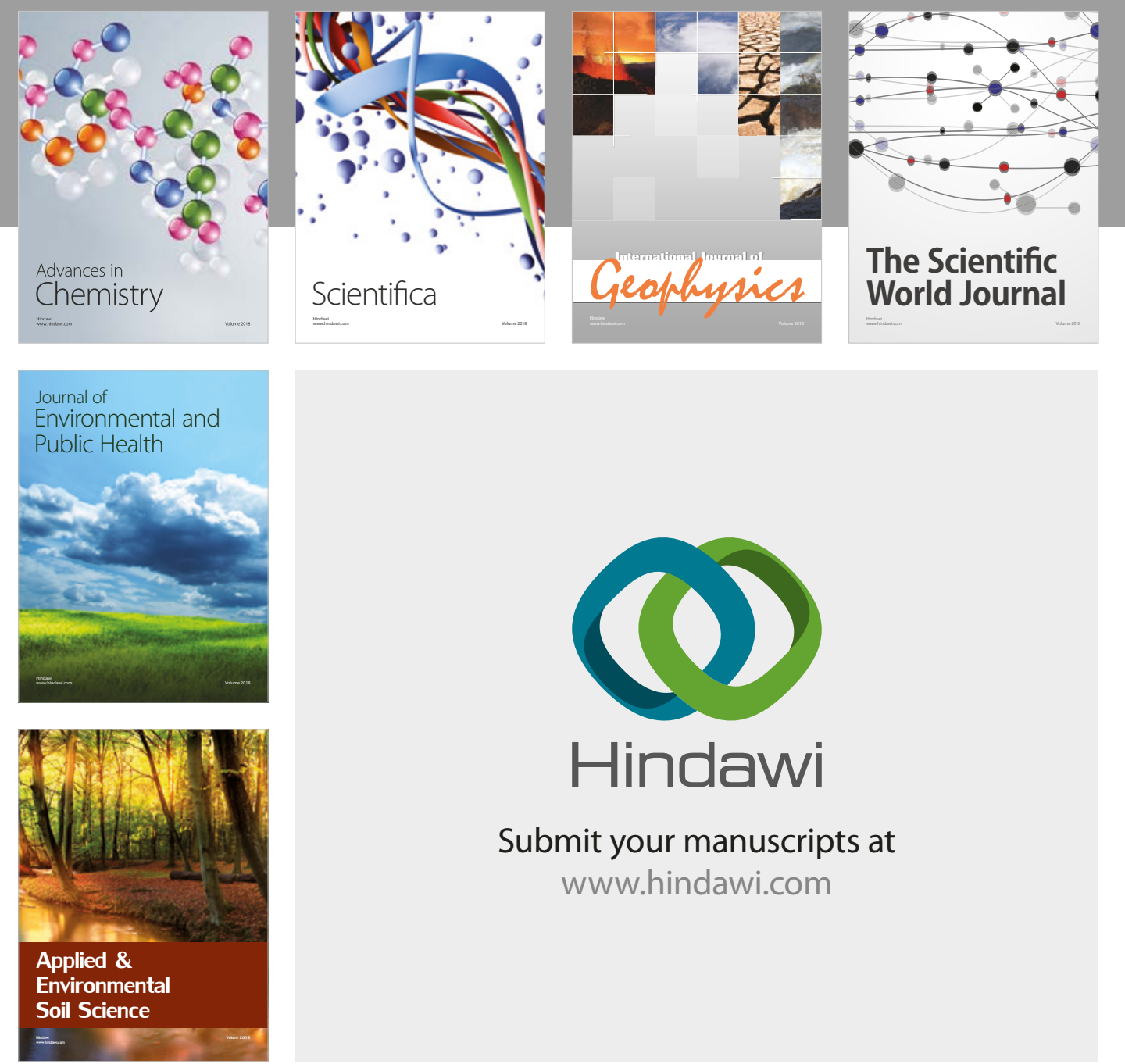

The Scientific

\section{World Journal}
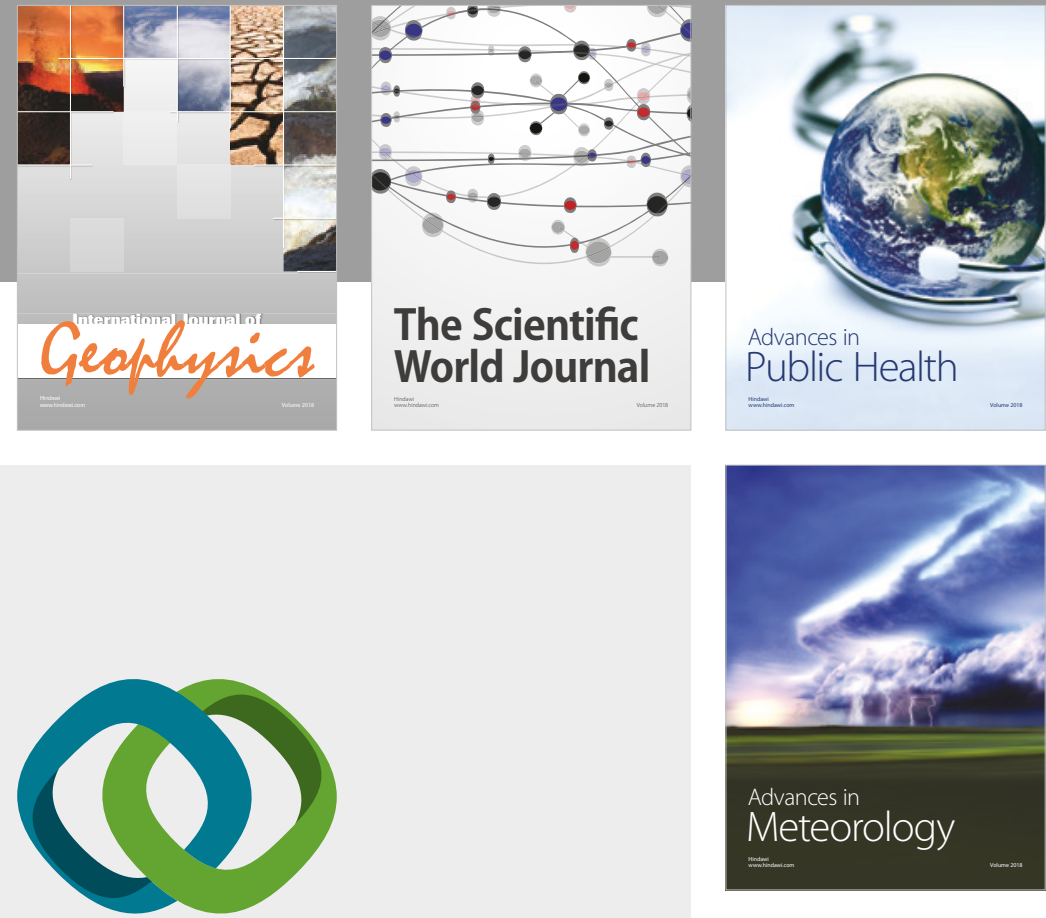

Advan

Public Health

\section{Hindawi}

Submit your manuscripts at

www.hindawi.com
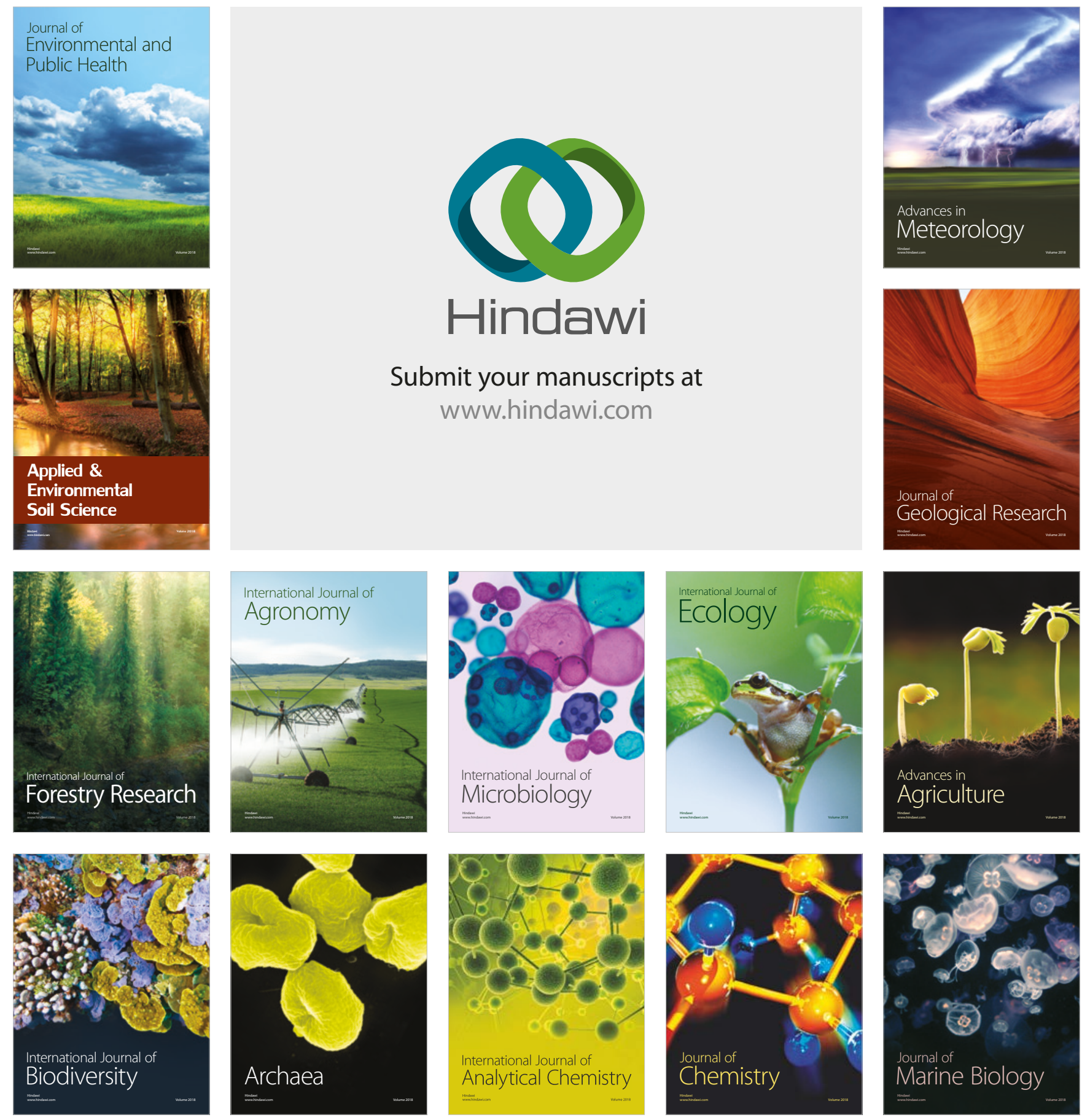